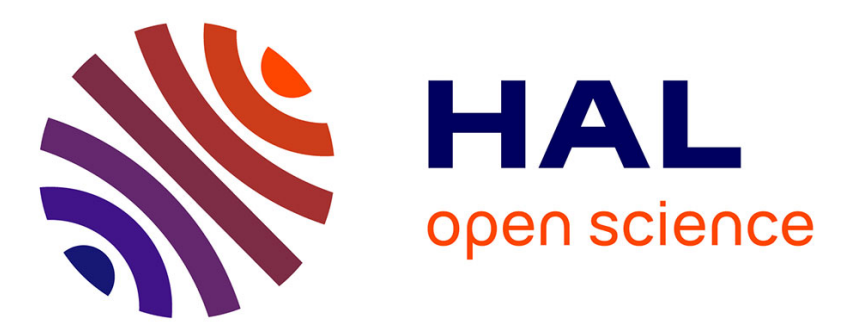

\title{
Hierarchy, coercion, and exploitation: An experimental analysis
}

Nikos Nikiforakis, Jörg Oechssler, Anwar Shah

\section{To cite this version:}

Nikos Nikiforakis, Jörg Oechssler, Anwar Shah. Hierarchy, coercion, and exploitation: An experimental analysis. Journal of Economic Behavior and Organization, 2014, 97, pp. 155-168. 10.1016/j.jebo.2013.06.008 . halshs-01098753

\section{HAL Id: halshs-01098753 \\ https://shs.hal.science/halshs-01098753}

Submitted on 7 Jan 2015

HAL is a multi-disciplinary open access archive for the deposit and dissemination of scientific research documents, whether they are published or not. The documents may come from teaching and research institutions in France or abroad, or from public or private research centers.
L'archive ouverte pluridisciplinaire HAL, est destinée au dépôt et à la diffusion de documents scientifiques de niveau recherche, publiés ou non, émanant des établissements d'enseignement et de recherche français ou étrangers, des laboratoires publics ou privés. 
Hierarchy, Coercion, and Exploitation:

An Experimental Analysis

Nikos Nikiforakis, Jörg Oechssler, Anwar Shah 


\section{GATE Groupe d'Analyse et de Théorie Économique Lyon-St Étienne}

93, chemin des Mouilles 69130 Ecully - France

Tel. +33 (0)4 72866060

Fax $+33(0) 472866090$

6, rue Basse des Rives 42023 Saint-Etienne cedex 02 - France

Tel. +33(0)4 77421960

Fax. +33 (0)4 77421950

Messagerie électronique / Email : gate@gate.cnrs.fr

Téléchargement / Download : http://www.gate.cnrs.fr - Publications / Working Papers 


\title{
Hierarchy, Coercion, and Exploitation: An Experimental Analysis*
}

\author{
Nikos Nikiforakis, Jörg Oechssler, and Anwar Shah ${ }^{\dagger}$
}

\begin{abstract}
The power to coerce workers is important for the efficient operation of hierarchically structured organizations. However, this power can also be used by managers to exploit their subordinates for their own benefit. We examine the relationship between the power to coerce and exploitation in a laboratory experiment where a senior and a junior player interact repeatedly for a finite number of periods. We find that senior players try repeatedly to use their power to exploit junior workers. These attempts are successful only when junior workers have incomplete information about how their effort impacts on the earnings of senior players, but not when they have complete information. Evidence from an incentive-compatible questionnaire indicates that the social acceptability of exploitation depends on whether the junior worker can detect she is being exploited. We also show how a history of exploitation affects future interactions.
\end{abstract}

JEL codes: C91, C72, D74.

Keywords: coercion, exploitation, disobedience, hierarchy, social norms.

\footnotetext{
${ }^{*}$ We would like to thank three referees and seminar participants at the Paris School of Economics, University of Hamburg, University of Heidelberg, University of Mannheim, University of Melbourne, and the Max-Planck Institute in Munich for helpful comments. Funding from the Faculty of Business \& Economics at the University of Melbourne and the University of Heidelberg is gratefully acknowledged.

${ }^{\dagger}$ Nikiforakis: (i) Department of Economics, The University of Melbourne, Victoria 3010, Australia; (ii) CNRS, Groupe d'Analyse et de Théorie Economique, 93, Chemin des Mouilles, 69130 Ecully, France; (iii) Max Planck Institute for Research on Collective Goods, Kurt Schumacher Strasse 10, 53113 Bonn, Germany, email: nikiforakis@gmail.com; Dechssler: Department of Economics, University of Heidelberg, Bergheimer Str. 58, 69115 Heidelberg, Germany, email: oechssler@uni-hd.de; Shah: School of Economics, Quaid-I-Azam University, 45320 Islamabad, Pakistan, email: anwar@qau.edu.pk.
} 


\section{Introduction}

Hierarchy is a nearly ubiquitous form of organization. Large multinational firms, small businesses, governmental agencies, and political parties are all hierarchically structured to some degree. A hierarchy typically implies that some individuals have the power to issue orders to others and punish those that disobey them. The power to coerce subordinates into taking specific actions is regarded as essential for the efficient operation of hierarchically structured organizations (e.g., Coleman, 1990; Day, 1963). However, individuals higher up in the hierarchy can abuse this power to their own benefit and exploit subordinates (e.g., Vafaï, 2002; Wertheimer, 1987).

The extent of exploitation in organizations is not precisely known. According to the European Values Survey, 50.2 percent of respondents stated that they felt exploited at work, at least sometimes. ${ }^{1}$ What is known, however, is that the exploitation of workers entails significant costs not only for the workers, but also for the organizations. Apart from the significant litigation costs, exploitation has been linked to reductions in workers' morale and productivity (Bewley, 1999), and to an increase in workplace aggression (Baron, Neuman, and Geddes, 1999; Hoad, 1993). The latter has been estimated to cost more than 1.75 million working days each year in the United States (Bachman, 1994).

Despite the importance of the topic, empirical evidence on exploitation in organizations is rare. One reason for this is that exploitation is usually either illegal or socially unacceptable, and thus hard to observe. Another important reason is that it can be difficult to determine what constitutes exploitation in daily life. In general, exploitation can be defined as the act of taking unfair advantage of another party (Wertheimer, 1996, 2008). ${ }^{2}$ However, determining what constitutes "unfair advantage" is not always straightforward as this typically depends on the context of an interaction and the history between the parties involved, which is often unobservable and unverifiable.

The paucity of empirical evidence implies that our knowledge regarding different factors that may facilitate exploitation is limited. For this reason, in this paper, we present evidence from a laboratory experiment exploring whether individuals use the power to coerce to exploit their subordinates to their own benefit and whether this depends on the ability of subordinates to detect that they are being exploited. While the laboratory environment undoubtedly differs in numerous ways from that in the field where exploitation occurs, it has the advantage that it allows one to examine situations where it is easier to establish what constitutes fair treatment of a worker and,

\footnotetext{
${ }^{1}$ The question on whether individuals felt exploited in their workplace was only included in the 1981 wave of the European Values Survey. In the past decade, the number of lawsuits due to labor exploitation has been steadily increasing (International Labour Organization, 2009).

${ }^{2}$ More specifically, Wertheimer (1996, p.16) defines exploitation as follows: "A exploits B when A takes unfair advantage of B. Taking unfair advantage could be understood in two ways. First, it may refer to some dimension of the outcome of the exploitative act or transaction, that is, the transaction is substantively unfair, and this, it seems has two elements: (1) the benefit to A and (2) the effect on B. We may say that the benefit to A is unfair because it is wrong for A to benefit at all from his act (e.g. by harming B) or because A's benefit is excessive relative to the benefit to B. Second, to say that A takes unfair advantage of B may imply that A has been able to turn some characteristic of B or some feature of B's situation to his or her advantage. We imply that there is some sort of defect in the process by which the unfair outcome has come about or the formation of the agreement between A and B, for example, that A has coerced B or defrauded B or has manipulated B."
} 
thus, what constitutes exploitation. Another advantage of using laboratory experiments is that they allow one to manipulate the environment to determine which factors may make exploitation more likely. For similar reasons, laboratory experiments have been previously used to study issues such as corruption, discrimination, and favoritism for which field data is also scarce (e.g., Abbink, 2006; Bernhard et al. 2006; Cameron et al. 2009; Castillo and Petrie, 2010). ${ }^{3}$

Our set up is as follows. A senior worker is placed in charge of a project. He must complete the project together with a junior worker. For simplicity, we will refer to the senior worker as "he" and the junior worker as "she". The two workers are equally efficient at work and the more effort the junior worker exerts on the project, the less effort the senior needs to exert. The senior worker makes a suggestion about how much effort the junior worker should exert. The junior worker is not bound by this suggestion and can disobey the senior worker by choosing to exert a different level of effort. The senior worker observes the junior worker's effort and has the power to punish her. He can use this power to try to ensure that the junior worker does not work less than he does, but he can also use it to coerce the junior worker into working more than him. Therefore, our set up allows us to establish a plausible benchmark for what constitutes fair treatment of the junior worker and what can be defined as exploitation. Like in most organizations, in our experiment, the two workers interact repeatedly for a finite number of periods. This implies that senior workers may have an incentive to invest in coercing the junior worker into exerting unfairly high levels of effort.

Our aim is to examine whether participants in the role of senior workers attempt to exploit junior workers, whether junior workers obey senior workers, and whether senior workers punish junior workers when they disobey their orders. We examine behavior under symmetric information, where junior workers know when they are exploited, and under asymmetric information, where the junior workers cannot detect exploitation. In addition, we employ a method developed by Krupka and Weber (in press) that uses an incentive-compatible questionnaire to elicit participants' normative views against exploitation and coercion, and how these views are affected by whether information is symmetric or asymmetric. Finally, we explore the impact of past exploitation on future outcomes. Field evidence indicates that (perceived) unfair treatment of a subordinate is associated with aggression against supervisors (e.g., Greenberg and Barling, 1999). In our experiment, after senior and junior workers have interacted for a finite number of periods, their roles are switched allowing us to explore how exploited workers behave when they find themselves in a position of power.

The experimental results indicate that participants in the role of senior workers systematically attempt to exploit junior workers. These attempts are much more pronounced under asymmetric information. In line with this behavior, responses to the incentive-compatible questionnaire indicate that senior workers consider higher-than-fair levels of effort more socially acceptable when there

\footnotetext{
${ }^{3}$ Laboratory experiments have also been used repeatedly to study topics in organizational economics. Some prominent examples are the investigation of gift-exchange relationships between employers and workers (e.g. Fehr, Kirchsteiger and Riedl, 1993), the adverse effects of monitoring workers (e.g., Falk and Kosfeld, 2006), factors that may facilitate coordination within firms (e.g., Brandts and Cooper, 2006; Weber, 2006), factors that may explain delegation (Hamman, Loewenstein, and Weber, 2010) and the impact of membership in organizational groups (Goette, Huffman, Meier, and Sutter, 2012).
} 
is asymmetric information. This is presumably because junior workers do not know they are being exploited. Despite the significant amounts of punishment in both treatments, exploitation is not successful under symmetric information as junior workers disobey the suggestions made by senior workers. Exploitation is successful under asymmetric information, although the extent of exploitation is small. The reason is that junior workers appear to anticipate that senior workers will try to exploit their informational advantage and disobey their suggestions. Disobedience is punished in both treatments, but substantially more under asymmetric information. As a consequence, junior workers with incomplete information are not only significantly worse off than senior workers, but also than junior workers who have complete information. Finally, we find that junior workers that have been exploited are more likely to attempt to exploit their subordinates when roles are reversed.

\section{The experiment}

\section{$2.1 \quad$ The game}

To address our research questions, we use a two-player, three-stage game. In stage one, the senior worker (Player S) makes a non-binding suggestion, $s$, regarding the effort level that he would like the junior worker (Player $J$ ) to choose in stage 2. In stage two, Player $J$ is informed about the level of effort suggested by Player S. Since the suggestion by Player S is non-binding, Player J may choose any effort level $e \in\{0,1, \ldots, 10\}$. The earnings of Player $\mathrm{S}$ are an increasing function of $e$ while the earnings of Player $\mathrm{J}$ are a decreasing function of $e$. Table 1 shows the pre-punishment earnings $\left(\hat{\pi}_{i}\right)$ of both players as a function of Player J's effort.

Table 1: Players' earnings as a function of effort chosen by Player J

\begin{tabular}{lccccccccccc}
\hline \hline$e$ & $0^{*}$ & 1 & 2 & $3^{\S}$ & 4 & 5 & 6 & 7 & 8 & 9 & 10 \\
\hline$\hat{\pi}_{S}$ & 12 & 14 & 16 & 18 & 20 & 22 & 24 & 26 & 28 & 30 & 32 \\
$\hat{\pi}_{J}$ & 24 & 22 & 20 & 18 & 16 & 14 & 12 & 10 & 8 & 6 & 4 \\
\hline Note: $^{*}$ denotes subgame-perfect solution for self-interested players; ${ }^{\S}$ denotes subgame-perfect solution for inequality- \\
averse (Fehr-Schmidt) players with $\alpha_{S}>1 / 4$ (Fehr and Schmidt, 1999).
\end{tabular}

In stage three, Player S receives information about the level of effort chosen by Player $\mathrm{J}$ and the associated earnings for both players. Having received this information, Player S can assign punishment points $p \in \mathbb{N}$ which would reduce Player J's earnings. Reducing Player J's earnings is costly for Player $\mathrm{S}$ who must sacrifice 0.2 units for every 1 unit he wishes to reduce J's earnings. That is, we employ a 1:5 fee-to-fine ratio, which should make punishment even more effective than usual. ${ }^{4}$ Player $\mathrm{S}$ cannot reduce Player J's earnings below 0 , that is, $p \leq \hat{\pi}_{J}$. Thus, the final earnings of both players at the end of a stage three are given by

\footnotetext{
${ }^{4}$ The fee-to-fine ratio was chosen so that punishment poses a non-negligable threat to the junior worker. In most experiments allowing for explicit punishment opportunities, the fee-to-fine ratio tends to be 1:3 (see e.g., Nikiforakis and Normann, 2008).
} 


$$
\begin{aligned}
& \pi_{S}=12+2 e-0.2 p \\
& \pi_{J}=24-2 e-p .
\end{aligned}
$$

Note that, without punishment, the game is a constant-sum game and efficiency concerns should play no role. This was done in order to control for subjects' concerns for efficiency and simplify the analysis of the data. ${ }^{5}$ Note also that an effort level of 3 equates the earnings of Player S and Player J. Given the saliency of equality in previous laboratory experiments and the fact that players are randomly assigned their roles in the experiment, $e=3$ could be regarded as the "fair level of effort." Therefore, in line with Wertheirmer's (1996, 2008) definition of exploitation, we will say that Player S exploits Player J when $e>3$. Accordingly, we will say that Player S attempts to exploit Player $\mathrm{J}$ if he suggests that Player $\mathrm{J}$ chooses an effort level greater than 3 . Finally, we will say that Player S coerces Player J if the latter disobeys Player S by choosing a lower level of effort than what was suggested by Player S and Player S punishes her. ${ }^{6}$

\section{$2.2 \quad$ Experimental treatments}

In the experiment, we investigate behavior in two treatment which differ with respect to the information available to Player J. In the baseline treatment, which we will call SYM, both players have symmetric information about the earnings functions of both players. In particular, the instructions contain both rows of Table 1 and formulas (1) and (2). In treatment ASYM (for asymmetric information), Player S is completely informed about Player J's earnings function. However, Player J knows only her own earnings function precisely (i.e. equation (1) and the $\hat{\pi}_{S}$-row are not contained in Player J's instructions). With respect to Player S's earnings, Player J knows only that there is a positive relationship between $e$ and Player S's earnings. This is common knowledge. Both players know about the effects and costs of punishment.

Participants in the experiment play the constituent game over 10 periods with the same partner. Note that the use of a fixed-matching protocol makes it possible for the senior to "invest" in punishment by punishing heavily in early periods in order to obtain the desired effort level. After each period, players are informed of their own earnings and how they were determined (i.e., $e, p$, but also $s$ ).

\footnotetext{
${ }^{5}$ This is in line with Tormey (1974) who writes that "Exploitation resembles a zero-sum game, viz. what the exploiter gains, the exploitee loses; or, minimally, for the exploiter to gain, the exploitee must lose." (p.207-208).

${ }^{6}$ This definition is consistent with that of Wertheimer (1996, p. 26) who states: "In general, A coerces B to do X only if A proposes (threatens) to make B worse off with reference to some baseline condition if B chooses not to do X, although specifying the appropriate baseline against which to measure the proposal can be a complicated matter." We take the suggestion of Player $\mathrm{S}$ as the baseline.
} 


\subsection{Related experimental literature}

The literature on exploitation is vast, mostly philosophical, and spans different disciplines. A thorough discussion of this literature is beyond our scope and would require a separate paper. The interested reader is referred to Wertheimer $(1996,2008)$. In this section, we review some related studies that use laboratory experiments.

In some respects, our game is similar to the well-studied ultimatum game, but with a number of important differences. The three most important are the following: (1) The non-binding suggestion in our game makes it possible for Player $\mathrm{S}$ to implicitly express a threat of the form "If you don't do as I say, then I will punish you," much like supervisors can in organizations. ${ }^{7}$ Therefore, unlike in the ultimatum game, the power to punish can be used not only to prevent unfairly low levels of effort by Player J, but also to coerce her into exerting unfairly high levels of effort. (2) Maximal punishment in our game leaves Player S with strictly positive earnings and Player $\mathrm{J}$ with zero earnings - a feature we believe is realistic of asymmetric relationships in the workplace and elsewhere. In contrast, in the ultimatum game, a rejection leaves both parties with zero earnings. (3) Like in most organizations, players in our experiment interact repeatedly. In contrast, in most ultimatum game experiments, subjects are randomly rematched in each period, and thus have no monetary incentive to invest in punishment.

Despite these differences, experiments in ultimatum games provide important insights about what one might expect to happen in our experiment. First, ultimatum games have established that the majority of participants in laboratory experiments have an aversion towards being taken advantage of and are thus willing to reject low offers (see e.g. Camerer, 2003). In anticipation of this, most offers tend to divide the surplus equally. However, when responders cannot monitor the fairness of the proposers' offers, the latter make low offers relative to when responders can observe the earnings of both players (Croson, 1996; Kagel, Kim, and Moser, 1996; Güth, Huck, and Ockenfels, 1996; Mitzkewitz and Nagel, 1993; Rapoport and Sundali, 1996; Rapoport, Sundali, and Seale, 1996; Schmitt, 2004; Straub and Murnighan, 1995). In general, responders accept these offers.

These findings suggest that participants in the role of Player S may try to exploit Player J. The latter may resist exploitation when there is symmetric information, but may "allow" to be exploited when she lacks information about the earnings of Player S. However, this need not be the case. First, unlike in our experiment where Player $\mathrm{J}$ has no information whatsoever about the earnings of Player S (in the ASYM treatment), responders in the aforementioned studies, know the possible realizations of the surplus and the probability distribution. This implies that they can make some inferences about whether the proposer is trying to exploit his informational advantage. Second, since the aforementioned ultimatum games do not involve repeated interactions, proposers do not have an incentive to invest in building a reputation; therefore, their offers reflect what they think responders will accept. In contrast, in our experiment, Player S has an incentive to suggest high

\footnotetext{
${ }^{7}$ Suggestions have been also shown to affect behavior even when not backed by a punishment threat. In a recent experiment, Andreoni and Rao (2011) show that if a receiver in a dictator game can suggest to the sender how much he should send, sending increases significantly.
} 
levels of effort and then punish Player $\mathrm{J}$ if they disobey their demands in order to achieve higher earnings in later rounds even under symmetric information. Our study therefore goes further by examining not only whether participants in the role of Player S attempt to exploit Player J, but also whether they are ready to coerce Player J in exerting higher levels of effort, and Player J's reaction.

Two closely related studies are Boles, Croson, and Murningham (2000) and Croson, Boles, and Murnighan (2003). These studies allow responders in an ultimatum game who are uninformed about the pie size to write open-ended messages to proposers, which, as it turns out, often take the form of threats. While "threats" and punishment are also possible in these studies, importantly, unlike in our game, it is the uninformed party who issues the threat and can punish by rejecting offers. The two games, therefore, model different situations. We believe that our set up is more relevant for understanding exploitation in organizations as managers usually have both more information than their subordinates and the power to coerce. ${ }^{8}$ We also note that while these studies also use fixed matching, individuals in Croson et al. and Boles et al. play 4 different games, each with a different pie size. Therefore, an action that may be perceived as selfish in one game, may actually be generous in another. This is not the case in our experiment where subjects play 10 times the same game.

The study most closely related to ours is that by Bolle, Breitmoser, and Schlächter (2011) who study extortion in a laboratory experiment using a finitely-repeated game between two players with symmetric information. In the first stage of the game, the first mover demands part of the other player's endowment. If the second mover accepts the demand in the second stage, then the game ends. If he rejects it, then the first mover can punish him. The threat posed by punishment is formidable. The first mover has to pay a fixed fee for punishing the second mover ( 25 percent of his endowment) and can reduce the latter's earnings by as much as he wishes. The authors find that the majority of demands implement equal earnings for the two players. Also, first movers are more likely to use maximal punishment. As a result, the probability their demand is accepted increases over time even though first movers become more demanding over the course of the experiment.

There are a number of differences between Bolle et al. (2011) and our study. First, Bolle et al. study behavior only under symmetric information, and not under asymmetric information. Second, there is a difference in the initial conditions, which could be important as it may affect subjects' views on what they are entitled to, their interpretation of the other player's intentions, and the norms governing behavior. ${ }^{9}$ Third, the punishment technology in Bolle et al. is much more severe than in our experiment. At the extreme, the fee-to-fine ratio is 1:16 compared to 1:5 in our experiment. Finally, we study how a history of exploitation affects the relationship between Player

\footnotetext{
${ }^{8}$ Although Boles et al. (1999) and Croson et al. (2003) vary the information conditions, the authors do not explore how threats and rejections vary across information conditions. In addition, we also study how the information conditions affect the social acceptability of exploitation.

${ }^{9}$ In particular, in Bolle et al. (2011), players are given endowments and the first mover can try to appropriate some of the second mover's endowment. This is the reason why Bolle et al.'s study is one of extortion. In our experiment, subjects are not given endowments. The first mover (Player S) simply suggests a level of effort. All else equal, we would expect second movers in our experiment to be more likely to accept the first mover's demands.
} 
$\mathrm{S}$ and $\mathrm{J}$ in future interactions when roles are reversed, and also elicit norms against exploitation using an incentive-compatible questionnaire, as we discuss below.

\subsection{Path dependence}

The experiment is divided into three parts. In Part 1, subjects play the game described in section 2.1. We are also interested to examine how past attempts to exploit Player $\mathrm{J}$ affect her behavior in the future. Does Player J retaliate when she has been coerced and exploited by Player S or does she let bygones be bygones? How does Player S react? This is an interesting question as in many organizations some young, talented, and energetic employees advance more quickly through the ranks than others and ultimately find themselves in a position of relative power. ${ }^{10}$ For this purpose, in Part 2 of the experiment, subjects' roles are reversed. Participants are not aware about the existence of Part 2, until Part 1 is completed. ${ }^{11}$

Part 2 of the experiment is identical in both treatments SYM and ASYM. That is, players have symmetric information in both cases. In Part 2, it is common knowledge that participants will play another 10 periods of the constituent game with their partners from Part 1.

\subsection{Norms against exploitation and coercion}

In the introduction, we stated our belief that exploitation is often socially unacceptable. Therefore, it is reasonable to expect that participants' behavior may be driven, at least partly, by norms against exploitation and coercion. To examine whether this is the case, whether participants hold similar views regarding the moral aspects underlying our game and how these views are affected by the information available to Player J, we elicit their views on the social acceptability of various hypothetical choices of effort levels and punishments in the third and final part of the experiment. Participants are informed about Part 3 at the end of Part 2 and are told that this would be the final part of the experiment.

To elicit social norms against exploitation and coercion, we follow a procedure introduced by Krupka and Weber (in press). ${ }^{12}$ Depending on the treatment, each participant is asked to characterize the suggestions of a hypothetical Player S (Adam) in Part 1 or the suggestions of a hypothetical Player J (Bob) in Part 2 as (1) very socially acceptable, (2) somewhat socially acceptable, (3) somewhat socially unacceptable, or (4) very socially unacceptable. ${ }^{13}$ For example, questions regarding

\footnotetext{
${ }^{10}$ This can certainly happen in academia. For example, consider a full professor who wishes to off-load a large undergraduate class to a new assistant professor. Although the suggestion is formally non-binding, the assistant professor realizes that various punishment possibilities are available to the senior (e.g. tenure decision). However, the assistant professor will eventually be promoted and may even become the head of the department which gives him power over the old professor. While this may take a few years, in other organizations where the age difference between employees is smaller, the power reversal may happen more quickly.

${ }^{11}$ The instructions read "You may receive further instructions later. If you do, please read those also carefully." The instructions for Part 2, however, explicitly said that the final Part 3 contains only a questionnaire.

${ }^{12}$ This method was also used recently by Burks and Krupka (2012) to investigate ethical norms in different steps of the hierarchy in a large financial services firm. Amongst other things, Burks and Krupka find that disagreement in views regarding ethical behavior can explain factors such as job dissatisfaction.

${ }^{13}$ In the experimental instructions, participants were told the following with regards to what is meant by "socially
} 
Part 1 are:

Suppose in Part 1, Bob knows exactly how Adam's earnings depend on Bob's effort choice. Adam asked Bob to choose an effort level of (3 or 5). How socially acceptable is Adam's demand?

In the ASYM treatment two additional questions are asked:

Suppose in Part 1, Bob does NOT know how Adam's earnings depend on Bob's effort choice. Adam asked Bob to choose an effort level of (3 or 5). How socially acceptable is Adam's demand?

A question regarding Part 2 is:

In Part 1, Adam asked Bob to choose an effort level of 5. Bob chose an effort level of 3. Adam reduced Bob's earnings until finally Bob chose a level of 5. In Part 2, Bob asked Adam to choose an effort level of (5 or 7 ). How socially acceptable is Bob's demand?

Following Krupka and Weber (in press), one of the questions is randomly selected at the end of the experiment. If a participant's answer matches that given by the majority of other participants in the experimental session, then he receives 5 Australian dollars (AUD) on top of his earnings from Part 1 and Part 2. If his answer does not match the majority answer, he receives nothing. The payment scheme provides individuals with incentives to reveal their beliefs about how socially acceptable a certain action is considered to be by the majority of participants in the experiment. Since social norms may be defined as "shared perceptions, among members of a population regarding the appropriateness of different behaviors" (Krupka and Weber, in press, p.4), the answers to the questionnaire should reveal the existence and content of norms against exploitation and coercion. ${ }^{14}$ The entire list of questions can be found in the appendix.

\subsection{Experimental procedures}

The experiments was conducted in the Experimental Economics Laboratory at the University of Melbourne between December 2009 and March 2010, using z-Tree (Fischbacher, 2007). Two sessions, each with 20 participants, were conducted for each treatment. Each session lasted approximately one hour forty-five minutes. Participants were invited from a database of approximately 2500 registered volunteer students using ORSEE (Greiner, 2004).

acceptable". "By socially acceptable, we mean decisions that most people would consider acceptable. A decision would be socially unacceptable if most people would consider it unacceptable."

${ }^{14}$ Of course, this game has multiple equilibria. The procedure works as intended only if subjects take their true belief about the majority's opinion as a focal point. 
Prior to entering the laboratory, each participant drew randomly a number from a hat. The number determined the participants' seat in the laboratory, their role in Part 1 of the experiment and their partner - the identity of whom was not revealed at any time before or after the experiment. Participants were then asked to read the instructions for Part 1. After reading the instructions for Part 1 (and later Part 2) participants completed a control questionnaire to check if they understood the instructions. Once all participants' answers were checked the experiment commenced. The instructions for Part 2 were distributed at the conclusion of Part 1. Similarly, the instructions of Part 3 were distributed at the end of Part 2.

Previous studies provide evidence suggesting that participants may behave in a more socially acceptable way (i.e., not attempt to exploit or coerce their subordinates) if the experimenter can identify their actions from their earnings (e.g., Hoffman et al., 1994). In order to minimize possible experimenter-demand effects, we used a double-blind protocol. One participant was assigned the role of the "monitor" based on the hat draw. The job of the monitor was to pay the participants at the end of the experiment. The experimenter was not present during the payment. Participants were told that the monitor would not read the instructions for Part 1 (and later for parts 2 and 3 ). Thus, the monitor was completely unaware about the game and could not infer whether participants behaved in a socially acceptable way; indeed, they could not even infer whether there was such a dimension to the experiment. The monitor only read a general set of instructions which was also provided to the other participants.

Earnings from the experiment were in Experimental Monetary Units (EMU) with an exchange rate of $9 \mathrm{EMU}=1$ Australian Dollar (AUD). Average earnings from the experiment amounted to approximately 40 AUD (or 22.85 AUD per hour). At the time of the experiment, the minimum national hourly wage rate was $14.31 \mathrm{AUD}$ and the exchange rate between the Australian and the US Dollar was approximately 1 . The monitor received a fixed payment of 30 AUD for assistance.

\subsection{Behavioral hypotheses}

We solve the 10-times repeated game by backward induction for two different behavioral assumptions. Assume first that it is common knowledge that players are only interested in their own material payoffs. Then there will be no punishment on the third stage as punishment reduces the earnings for Player S (i.e., $p=0$ ). Hence, on the second stage, Player J will choose the minimal effort of $e=0$. On the first stage, Player S may make any suggestion regarding the desired effort level since this is only cheap talk. The resulting earnings are $\pi_{S}=12$ and $\pi_{J}=24$. This prediction holds under both symmetric and asymmetric information (i.e., both in treatments SYM and ASYM). Since this is the unique subgame-perfect equilibrium of the constituent game, a well-known result (see e.g. Oechssler, 2013) implies that the 10-period game has a unique subgame-perfect equilibrium which consists of playing the unique subgame-perfect equilibrium of the constituent game in every period.

Let us now assume that players dislike inequality in earnings. In particular, let us assume 
Fehr-Schmidt preferences (Fehr and Schmidt, 1999). The utility of player $i$ is given by

$$
u_{i}=\Pi_{i}-\alpha_{i} \max \left[\Pi_{j}-\Pi_{i}, 0\right]-\beta_{i} \max \left[\Pi_{i}-\Pi_{j}, 0\right]
$$

with $0 \leq \beta_{i}<1$ and $\beta_{i} \leq \alpha_{i}$. This model is a natural choice for our purposes as it assumes that (some) players may dislike being treated unfairly.

As pointed out by Oechssler (2013), when a constituent game is repeated a finite number of times with social preferences, one cannot rely, in general, on the above result since preferences are interdependent across periods. This is why we have to use the sum of payoffs $\Pi_{i}=\sum_{t} \pi_{i}^{t}$ in (3).

Consider first the case of symmetric information. We solve the repeated game by backward induction. Consider stage 3 of the last period. Given that 5 units of punishment reduce $\Pi_{J}$ by 5 and $\Pi_{S}$ by 1 , the payoff difference is being reduced by 4 . Hence, if $\alpha_{S}>1 / 4$, Player $\mathrm{S}$ will use punishment to reduce as much as possible the inequality in material payoffs, that is, he will try to minimize the second term in (3). This implies that there will be no punishment, if payoffs are (weakly) in favor of Player S because punishment would only increase the payoff difference between Player S and Player J and would therefore never be used for any $\beta_{S} \geq 0$. Assuming Player J knows that $\alpha_{S}>1 / 4$ and that she considers her own earnings as more important than that of Player $\mathrm{S}$ (i.e., $\beta_{J}<1 / 2$ ), her best response on stage 2 is to choose an effort such that payoffs are as equal as possible. ${ }^{15}$ Intuitively, it is better for Player $\mathrm{J}$ to equalize payoffs herself rather than wait for Player S to equalize payoffs through punishment. In particular, if earnings so far have been equal, Player J will choose $e=3$. Again, Player S may demand any level of effort in stage 1 .

Given this behavior in the last period, one can check that there is a unique set of subgameperfect equilibria which has the properties that (1) punishment is not used on the equilibrium path and (2) both players receive the same payoff on the equilibrium path. One of those equilibrium paths is focal as it involves a constant effort of $e=3$ in each period. The resulting earnings in the constituent game are $\pi_{S}=18$ and $\pi_{J}=18$. But there are also SPE in which, for example, Player $\mathrm{J}$ chooses $e=2$ in one period and makes up for this with $e=4$ in another period. However, the average effort over all 10 periods must be 3 .

Under asymmetric information, if Player $\mathrm{S}$ is sufficiently averse to disadvantageous inequality (i.e., $\alpha_{S}>1 / 4$ ), having complete information about the earnings of both players, he will punish Player J to equalize payoffs. However, Player $\mathrm{J}$ has no information about how her effort impacts the earnings of Player S. Therefore, we cannot offer a clear prediction about how asymmetric information may affect outcomes if players are inequality averse. Based on the evidence discussed in section 2.3, we expect Player S to be more likely to attempt to exploit Player J in ASYM than in SYM.

To summarize, both theories predict that average effort is less than or equal to 3. Punishment is only predicted by the Fehr-Schmidt model when average effort is less than 3 and Player S cares sufficiently about disadvantageous inequality (i.e., $\alpha_{S}>1 / 4$ ). Punishment is predicted to be

\footnotetext{
${ }^{15}$ If Player $J$ is sufficiently concerned about inequality in her favor (i.e., $\beta_{J}>1 / 2$ ), she would choose an effort to equalize payoffs without the threat of punishment (i.e. even if $\alpha_{S}<1 / 4$ ).
} 


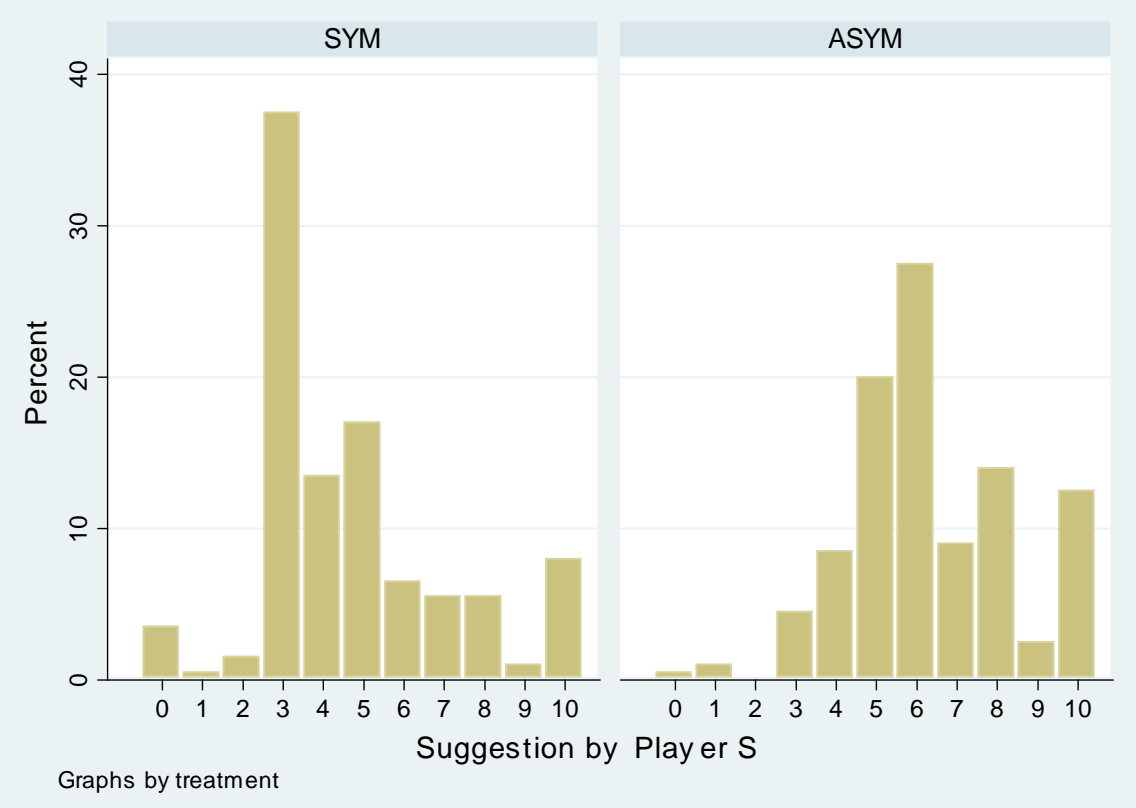

Figure 1: Suggestions made by Player S in Part 1

unrelated to the suggestions made by Player S.

\section{Results}

Result 1: Player $S$ attempts to exploit Player $J$ in both treatments. Attempts to exploit are more pronounced under asymmetric information.

SUPPORT: Figure 1 presents a histogram with the suggestions made by participants assigned the role of Player $S$ in the first part of the experiment (periods 1-10) in each treatment. Suggestions are visibly higher in ASYM than in SYM. The average (median) suggestion is 4.66 (4) in SYM and 6.35 (6) in ASYM. The modal suggestion is 3 in SYM and 6 in ASYM. The difference is statistically significant using the average suggestion across periods 1-10 in each group as an independent observation (Mann-Whitney, two-tailed, $p$-value $<0.01$ ). The difference in suggestions is apparent even in period 1 (4.65 in SYM and 6.20 in ASYM; Mann-Whitney, two-tailed, $p$-value $=0.03$ ), showing that participants in the role of Player S understand incentives in the game and that they are willing to use the informational advantage to their benefit. Suggestions remain fairly stable across the ten periods in Part 1 (Spearman: $\rho=-0.03, p$-value $=0.93$ for $\mathrm{SYM} ; \rho=-0.10, p$-value $=0.79$ for ASYM).

The data summarized in Figure 1 are somewhat puzzling. On the one hand, they indicate clearly that most participants in the role of Player S are not concerned much about (advantageous) inequalities in earnings as they attempt to exploit their informational advantage in ASYM to earn higher amounts than Player J. On the other hand, however, participants make fairly low suggestions 
under symmetric information, despite the fact that they can coerce Player J into exerting higher effort. Why is this? One possibility is that subjects' behavior is affected by social norms related to exploitation, and that the norms prescribe different actions under different information conditions. Therefore, before we examine the effort exerted by Player J, we take a look at the answers to the norm questionnaire. What level of effort do individuals in the role of Player $\mathrm{S}$ believe to be socially acceptable and what level to be socially unacceptable? Most participants in the role of Player S in both treatments find an effort of 3 (the level that equalizes pre-punishment earnings) to be very socially acceptable. ${ }^{16}$ More interestingly, however, is the response to the question how socially acceptable do those in the role of Player S find effort levels of 5 , which imply $\hat{\pi}_{S}>\hat{\pi}_{J}$. The average rank is 2.30 in SYM and 1.45 in ASYM. The difference is statistically significant (Mann-Whitney, $p$-value $<0.01$ ). These responses indicate that those in the role of Player $\mathrm{S}$ in treatment ASYM believe that when exploitation cannot be detected it is less socially unacceptable. This is presumably because Player $\mathrm{J}$ does not feel that she is being exploited. This provides an explanation for the more frequent attempts to exploit in Part 1 which, to our knowledge, has not been previously documented in the literature.

Result 2: On average, attempts to exploit are unsuccessful under symmetric information. Player $S$ succeeds in exploiting Player $J$ under asymmetric information, but the extent of exploitation is relatively small. Nevertheless, those in the role of Player $J$ are worse off under asymmetric information than under symmetric information.

SUPPORT: The average (median) effort level is 3.03 (3) in SYM and 3.64 (4) in ASYM (see Figure 2 ). The difference is (weakly) significant (Mann-Whitney, two-tailed, $p$-value $=0.07$ ). Further, using the average effort level in each group in periods 1-10 as an independent observation, we fail to reject the hypothesis that the effort level in SYM is significantly different from 3, which would equalize the earnings of Player S and J (Wilcoxon signed-rank test, two tailed, $p$-value $=0.49)$. Thus, according to our definition, we do not detect exploitation in the SYM treatment. In contrast, the average effort level in ASYM is significantly higher than 3 (Wilcoxon signed-rank test, two tailed, $p$-value $=0.03$ ) and documents at least a small level of exploitation. Effort levels remain fairly stable across the ten periods in Part 1 (Spearman: $\rho=0.20, p$-value $=0.59$ for SYM; $\rho=-0.28, p$-value $=0.44$ for ASYM).

The result of exploitation is that the pre-punishment earnings of senior subjects in the first part of the experiment are 19.28 EMU, while that of junior subjects are 16.72 EMU. This difference is (weakly) statistically significant (Wilcoxon signed-rank test, two-tailed, $p$-value $=0.09$ ). The difference in pre-punishment earnings of senior and junior subjects in SYM is negligible (18.05 EMU and 17.95 EMU for senior and junior subjects, respectively) and not statistically significant

\footnotetext{
${ }^{16}$ The answers were coded as 1 for "very socially acceptable, 2 for "somewhat socially acceptable", 3 for "somewhat socially unacceptable", and 4 for "very socially unacceptable". In particular, all participants in the role of Player $\mathrm{S}$ in treatment SYM said that an effort of 3 is very socially acceptable (average rank =1). Similarly, 75 percent of those assigned the role of Player S in ASYM said that an effort of 3 is very socially acceptable while a further 15 percent said that it was somewhat socially acceptable (average rank $=1.35$ ). Despite being small in magnitude, the difference is statistically significant (Mann-Whitney, $p$-value $=0.02$ ).
} 


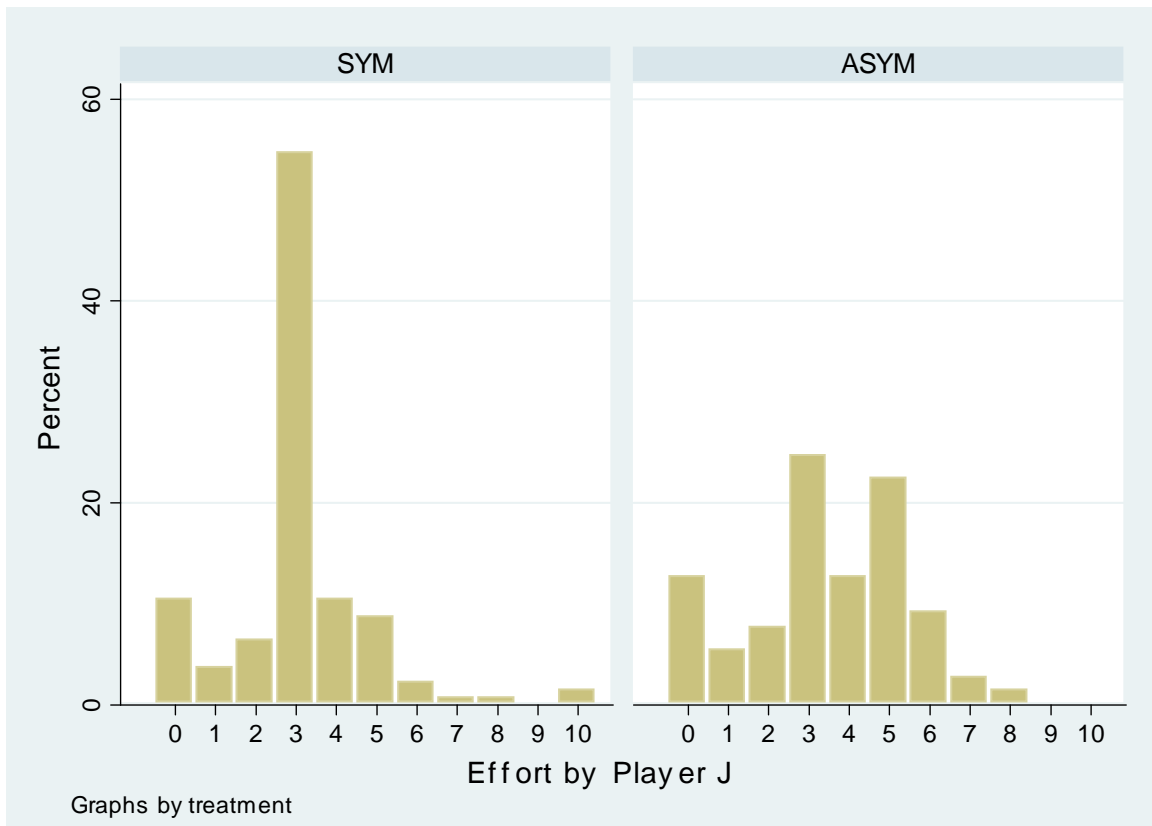

Figure 2: Effort exerted by Player J in Part 1

(Wilcoxon signed-rank test, two-tailed, $p$-value $=0.81$ ). The post-punishment earnings of junior subjects in ASYM (12.41 EMU) are significantly lower than those of junior subjects in SYM (15.46; Mann-Whitney, two-tailed, $p$-value $<0.01)$.

Result 3: The reason why exploitation is relatively small under asymmetric information is that those in the role of Player J show more disobedience with respect to the suggestions made by Player $S$.

SUPPORT: We define effort deviation as the difference between the suggestion by Player S and the effort exerted by Player J. Effort deviation is a measure of disobedience. ${ }^{17}$ The average effort deviation in periods 1-10 is 1.63 in SYM and 2.72 in ASYM. Using the average of each group in periods 1-10, we find that the difference across treatments is statistically significant (MannWhitney, two-tailed, $p$-value $=0.04$ ). Those in the role of Player J seem to anticipate that Player S will attempt to use the asymmetric information to their advantage already in the first period. The average effort deviation in period 1 is 1.80 in SYM and 2.55 in ASYM (Mann-Whitney, two-tailed, $p$-value $=0.11)$. Even though suggestions are higher in the ASYM than in the SYM treatment, Player J's greater willingness to disobey Player S in the ASYM treatment seems surprising, given that Player J does not have any information about Player S's earnings.

\footnotetext{
${ }^{17}$ As one would expect, effort deviation is almost always positive or zero, i.e., Player J almost never exerts effort higher than what was suggested to them. In particular, out of 200 observations ( 20 groups * 10 periods) in the first part of the experiment in each treatment, there are only 6 instances of negative effort deviation all of which occurred in SYM.
} 




Figure 3: Distribution of punishment points assigned by Player S in Part 1

According to the theoretical predictions discussed in Section 2.7, suggestions (or disobedience) should not be correlated with punishment. However, as the next result shows, this turns out not to be the case.

Result 4: In both treatments, Player $S$ coerces Player $J$ by punishing her when she disobeys his suggestion. Coercion is substantially more severe under asymmetric information, even when we control for the extent of disobedience. In both treatments, coercion has a relatively small but positive effect on effort.

SUPPORT: Most participants in the role of Player S use punishment at some point in Part 1. In particular, 15 of the 20 senior subjects punish at least once in SYM and 18 out of 20 senior subjects do so in ASYM. The average number of punishment points assigned is larger in ASYM than in SYM (4.10 versus 2.49). This is a sizeable difference suggesting that participants in ASYM are willing to coerce those in the role of Player $\mathrm{J}$ into exerting higher levels of effort. However, this may be a premature conclusion if this difference is driven by the greater extent of disobedience in ASYM (see Result 3).

Figure 3 shows the distribution of punishment points assigned by Player S in Part 1 of the experiment. In many rounds there is no punishment at all. If there is punishment, it seems to be fairly spread out over all possible punishment levels with peaks on prominent numbers like 5 and 10. The frequency of maximal punishment is small (1.8\% in SYM and $7.0 \%$ in ASYM). ${ }^{18}$

\footnotetext{
${ }^{18}$ This is not shown in Figure 3 since maximal punishment depends on the pre-punishment earnings of player J.
} 
Table 2: What determines punishment? Tobit random effects regression

\begin{tabular}{|c|c|c|c|}
\hline dependent variable: punishment points & SYM & ASYM & pooled \\
\hline \multirow{2}{*}{ effort deviation $(s-e)$} & $1.60^{* * *}$ & $0.95^{* *}$ & $1.62^{* * *}$ \\
\hline & $(0.40)$ & $(0.47)$ & $(0.39)$ \\
\hline \multirow{2}{*}{$\max [0$, effort -3$]$} & -1.45 & -1.19 & -1.61 \\
\hline & $(1.22)$ & $(0.80)$ & $(1.24)$ \\
\hline \multirow{2}{*}{$\max [0,3$-effort $]$} & $4.36^{* * *}$ & $5.38^{* * *}$ & $4.34^{* * *}$ \\
\hline & $(0.84)$ & $(1.13)$ & $(0.80)$ \\
\hline \multirow{2}{*}{ period } & 0.19 & $-0.47^{*}$ & 0.19 \\
\hline & $(0.26)$ & $(0.25)$ & $(0.26)$ \\
\hline ASYM & & & $\begin{array}{l}7.23^{* *} \\
(3.52)\end{array}$ \\
\hline ASYM * effort deviation & & & $\begin{array}{c}-0.63 \\
(0.59)\end{array}$ \\
\hline $\mathrm{ASYM} * \max [0$, effort -3$]$ & & & $\begin{array}{c}0.48 \\
(1.45)\end{array}$ \\
\hline $\mathrm{ASYM} * \max [0,3$-effort $]$ & & & $\begin{array}{c}0.97 \\
(1.30)\end{array}$ \\
\hline ASYM * period & & & $\begin{array}{c}-0.67^{*} \\
(0.36)\end{array}$ \\
\hline constant & $\begin{array}{c}10.71^{* * *} \\
(2.71)\end{array}$ & $\begin{array}{l}-3.58 \\
(2.90)\end{array}$ & $\begin{array}{c}-10.86^{* * *} \\
(2.59)\end{array}$ \\
\hline
\end{tabular}

Note: Standard errors in parentheses. Punishment is censored at 0 and at the pre-punishment earnings of Player J. ${ }^{* * *},{ }^{* *},{ }^{*}$ significant at 1\%, 5\%, 10\% level; $N=200$ (SYM and ASYM), 400 (pooled).

Table 2 presents the results from a regression analysis on the determinants of punishment. The dependent variable is the number of punishment points that Player $\mathrm{S}$ assigned to Player $\mathrm{J}$ in period $t$. Since punishment is censored at 0 and at the pre-punishment earnings of player J, we use a Tobit regression. The independent variables are: effort deviation - the difference between the suggestion made by Player S and the effort chosen by Player J; , effort - the level of effort exerted by Player J in period $t$, where we allow for asymmetric affects for efforts higher than 3 and lower than 3 ; period - a variable controlling for possible time trends; for the pooled regression we also include $A S Y M$ - a treatment dummy taking the value of 1 if the observation comes from the ASYM treatment and 0 otherwise. We also include the interaction of the above variables with the treatment dummy. The empirical model controls for individual random effects taking into account the fact that each individual makes repeated decisions regarding punishment.

The most robust finding in all regressions of Table 2 is that disobeying Player $\mathrm{S}$ by choosing a level of effort below what was suggested is punished in both treatments (cf. the strongly significant coefficients for effort deviation). Another interesting finding is that, even when controlling for the extent of disobedience, punishment is substantially and significantly higher in ASYM than in SYM. This can be seen by the sizable treatment dummy for ASYM. This suggests that participants in the role of Player S use the asymmetric information to force Player $J$ to exert higher levels of effort. As one would expect, the higher the level of effort exerted by Player $\mathrm{J}$ the less is the punishment that 
is meted out. However, this effect is only significant for effort levels below 3. The insignificance of the interactions of the effort variables and $A S Y M$ indicates that lower effort is not punished more in ASYM than in SYM.

Is coercion successful? Does Player J respond to punishment by increasing her effort in the following period? Table 3 presents the results from linear random effects regressions analyzing the determinants of effort exerted by Player J. The dependent variable is the effort exerted in period $t$. The independent variables are Suggestion in $t$ by Player S, Punishment in $t-1$, i.e., the number of points Player S assigned to Player $\mathrm{J}$ in the previous period, and Period. All variables are used as first differences. The results indicate that Player J responds strongly to the suggestion made by Player S. In contrast to some of the recent literature (e.g. Bolle et al., 2011; Denant-Boemont et al., 2007; Fehr and Rockenbach, 2003; Nikiforakis, 2008), we find no counter-productive effect of punishment. The effect of past punishment is significantly positive in all regressions, although its magnitude is fairly small.

Table 3: What determines effort? Random effects regression

\begin{tabular}{lccc}
\hline \hline dependent variable: effort in $t$ & SYM & ASYM & pooled \\
\hline \multirow{2}{*}{ suggestion in $t$} & $0.38^{* * *}$ & $0.30^{* * *}$ & $0.38^{* * *}$ \\
& $(0.06)$ & $(0.08)$ & $(0.07)$ \\
punishment in $t-1$ & $0.06^{* * *}$ & $0.05^{* *}$ & $0.06^{* *}$ \\
period & $(0.02)$ & $(0.02)$ & $(0.03)$ \\
& 0.00 & 0.01 & 0.00 \\
ASYM & $(0.15)$ & $(0.20)$ & $(0.17)$ \\
& & & 0.01 \\
ASYM * suggestion in $t$ & & & $(0.24)$ \\
& & & -0.08 \\
ASYM * punishment in $t-1$ & & & $-0.10)$ \\
\end{tabular}

Note: Standard errors in parentheses. All variables in the regression were used as first differences. ${ }^{* * *},{ }^{* *},{ }^{*}$ significant at 1\%, 5\%, 10\% level; $N=160$ (SYM and ASYM), 320 (pooled).

We next turn our attention to behavior in the second part of the experiment after roles are reversed. In SYM, the role reversal does not reveal any new information about the payoffs realized by the senior subjects in periods 1-10. In contrast, in ASYM, junior subjects learn the extent to which they have been exploited. We are interested to see to what extent behavior in periods 1-10 affects outcomes in periods 11-20.

Result 5: Behavior in Part 2 is significantly determined by the outcomes in Part 1 in ASYM. There is a similar, but weaker, relationship in $S Y M$.

SUPPORT: Figures 4 and 5 presents the relationship between effort exerted by Player $\mathrm{J}$ in periods 1-10 and that exerted by Player S in periods 11-20. Each observation represents the average effort in a group in periods 1-10 and the average effort in periods 11-20. The two lines represent the 


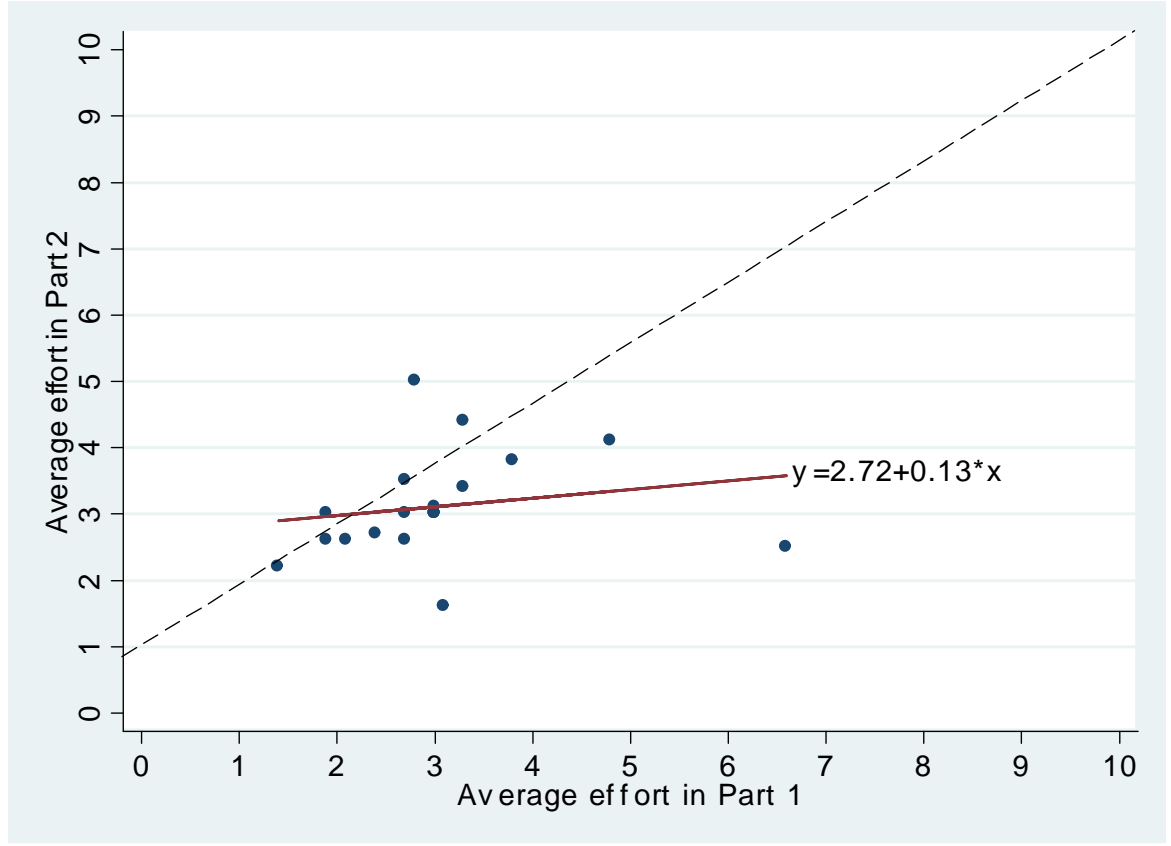

Figure 4: Effort in Parts 1 and 2 in treatment SYM

45-degree line and a fitted regression line. As can be seen, there is a clear positive relationship in ASYM. The relationship is weaker in SYM, although clearly effort in the second part of the experiment is still similar to that in the first part in some groups. To assess the strength of the relationship we ran an OLS regression. The dependent variable is the average effort in periods 11-20. The independent variable is the average effort in periods 1-10. The relationship is highly significant in ASYM (coefficient: $0.68 ; p$-value < 0.01), but not in SYM (coefficient: 0.13; $p$-value $=0.44) .{ }^{19}$ These findings suggest that bygones are not bygones.

In order to understand behavior in Part 2 and how it relates to that in Part 1, we take a look at the responses provided by individuals in the role of Player $\mathrm{J}$ in the norm questionnaire. The answers illustrate that, in both treatments, those in the role of Player J consider "an eye for an eye" to be socially acceptable and "two eyes for an eye" to be socially unacceptable. We also find that "letting bygones be bygones" is as socially acceptable as "an eye for an eye". In particular, individuals were asked three questions:

"In part 1, Adam asked Bob to choose an effort level of 5. (Bob did not know how his effort will affect Adam's earnings - ASYM only.) Bob chose an effort level of 3. Adam reduced Bob's earnings until finally Bob chose a level of 5. In Part 2, Bob asked Adam to choose an effort level of 5. How socially acceptable is Bob's demand?"

"In part 1, Adam asked Bob to choose an effort level of 5. (Bob did not know how his effort

\footnotetext{
${ }^{19}$ One group in SYM appears to be an outlier with an average effort close to 7 in the first part and below 3 in the second part. If we run the regression excluding this group, the relationship becomes significant, although it is still weaker than in ASYM (coefficient: $0.53 ; p$-value $=0.03$ ).
} 


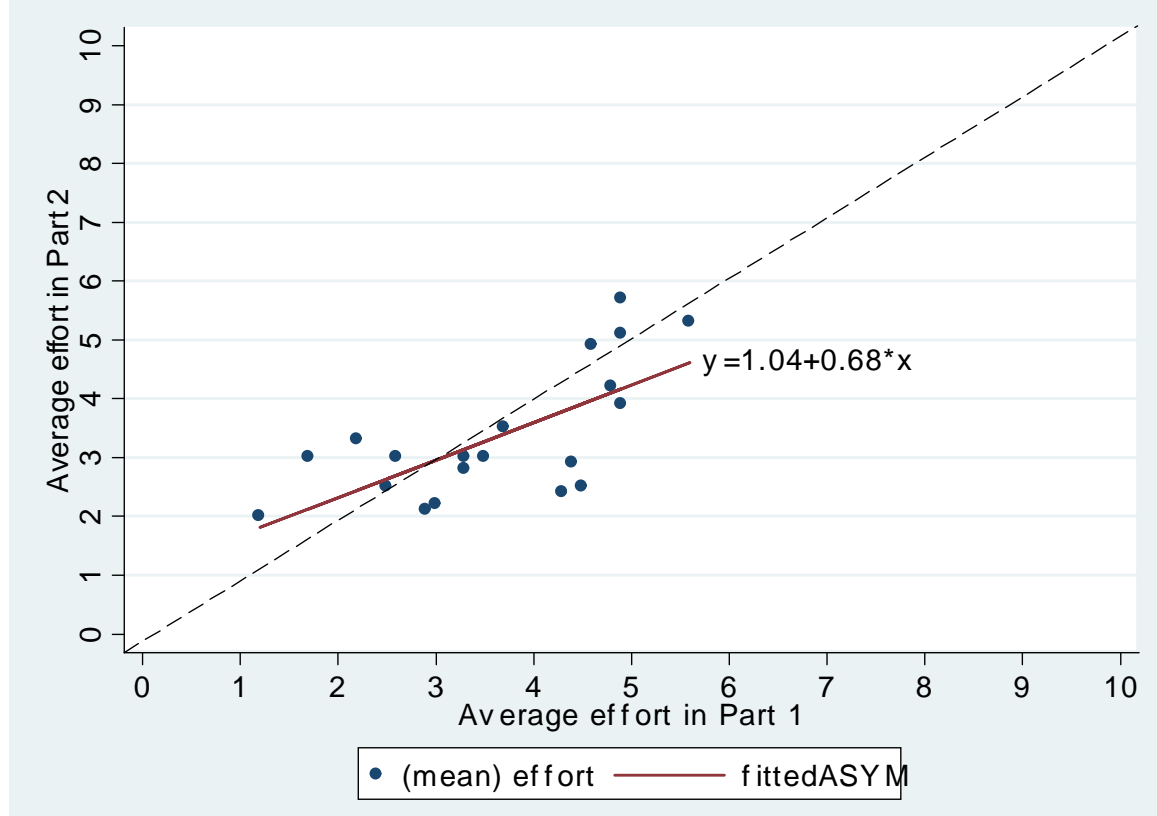

Figure 5: Effort in Parts 1 and 2 in treatment ASYM

will affect Adam's earnings - ASYM only.) Bob chose an effort level of 3. Adam reduced Bob's earnings until finally Bob chose a level of 5. In Part 2, Bob asked Adam to choose an effort level of 7 instead. How socially acceptable is Bob's demand?"

"In part 1, Adam asked Bob to choose an effort level of 5. (Bob did not know how his effort will affect Adam's earnings - ASYM only.) Bob chose an effort level of 5. Adam did not reduce Bob's earnings. In Part 2, Bob asked Adam to choose an effort level of 3 instead. How socially acceptable is Bob's demand?

Again answers were coded as 1 for "very socially acceptable, 2 for "somewhat socially acceptable", 3 for "somewhat socially unacceptable", and 4 for "very socially unacceptable". The average rank for the first question is 1.60 and 1.65 for SYM and ASYM, respectively. The average rank for the second question is 3.10 and 3.05 for SYM and ASYM, respectively. The average rank for the third question is 1.55 and 1.70 for SYM and ASYM, respectively. None of the three differences across treatments are statistically significant using a two-tailed Mann-Whitney test ( $p$-values $>0.65)$. The average rank is significantly higher in the second question than in the first question using a two-tailed Wilcoxon test ( $p$-value $<0.01$ for both SYM and ASYM) suggesting that "an eye for an eye" is more socially acceptable than "two eyes for an eye". Also, the average rank is significantly lower in the third question than in the second question again using a two-tailed Wilcoxon test ( $p$-value $<0.01$ for both SYM and ASYM) suggesting that letting bygones be bygones in the absence of coercion is more socially acceptable than "two eyes for an eye". However, the average rank is not significantly different in the first and third questions using a two-tailed Wilcoxon test $(p$-value $>0.74)$. 


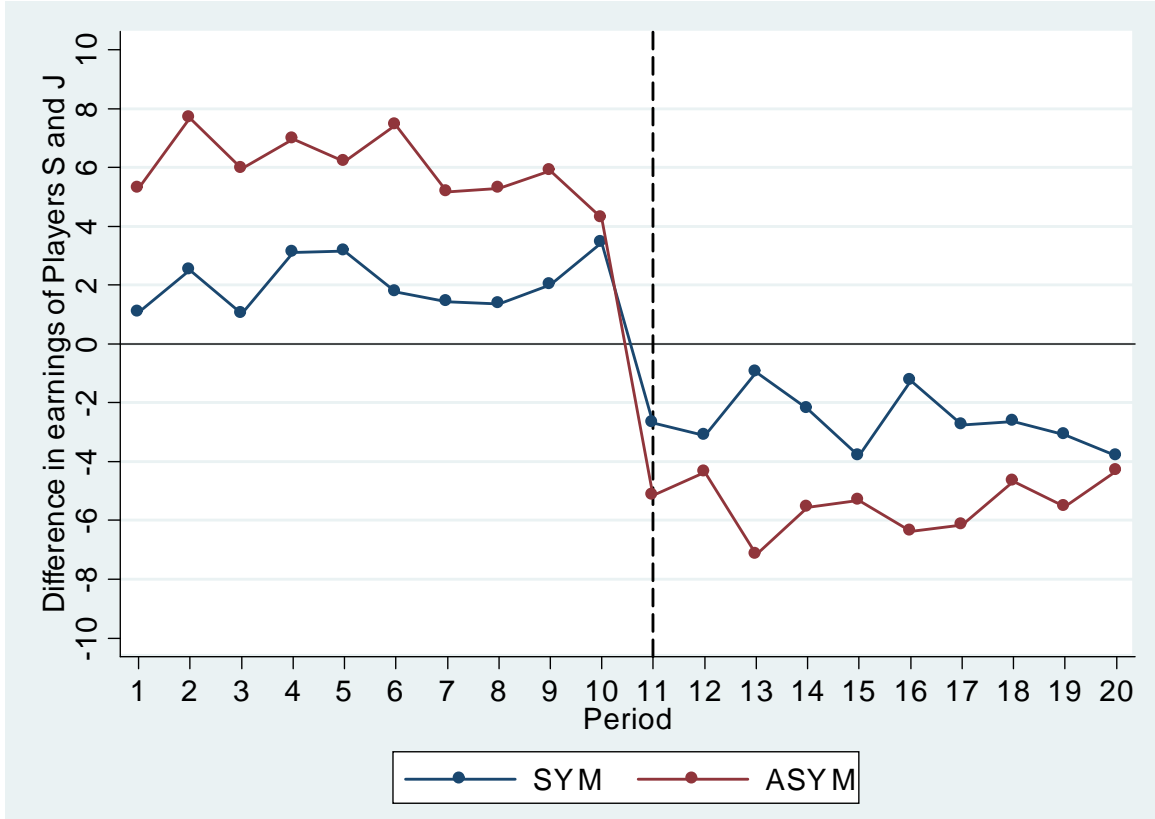

Figure 6: Differences in earnings before and after the role change

It is also interesting to examine the relationship between post-punishment earnings in the first and second part of the experiment. Post-punishment earnings reveal the extent of inequality between Player S and Player J, but also, given the evidence just presented on effort, the extent of punishment. Figure 6 plots the difference in the average post-punishment earnings between Player $\mathrm{S}$ and Player $\mathrm{J}$ in the first and second part. The figure illustrates that Player $\mathrm{S}$ earns more than Player $\mathrm{J}$ in both treatments in Part 1, while the opposite happens in Part 2. It also depicts that the difference in earnings is greater under asymmetric information. Finally, it reveals that the outcomes in the first part of the experiment are positively correlated with the outcomes in the second part under asymmetric information. The relationship is again weaker in SYM. To assess the strength of the relationship we ran an OLS regression. The dependent variable is the average difference in earnings in periods 11-20. The independent variable is the average effort in periods 1-10. The relationship is highly significant in ASYM (coefficient: 0.75; $p$-value $<0.01$ ), but not in SYM (coefficient: $0.27 ; p$-value $=0.15$ ).

What makes these results interesting is the fact that subjects have symmetric information in both treatments in the second part. Exploitation in the first part clearly affects outcomes in the second part in ASYM. Nevertheless, effort in the second part is not significantly different across treatments (Mann-Whitney, two-tailed, $p$-value $=0.83$ ). Also, we cannot reject the hypothesis that the average effort of 3.10 in SYM and 3.37 in ASYM is the same as the "fair" effort level of 3 (Wilcoxon signed-ranks test, two-tailed, $p$-value $>0.46$ ). 


\section{Conclusion}

We have designed a game in which exploitation can result from the hierarchical relationship between players and, in particular, from the fact that the senior worker has the power to coerce a junior worker into exerting high levels of effort. Using a laboratory experiment, we find that senior workers often attempt to exploit junior workers, asking them to exert high levels of effort. This occurs both when junior workers have complete information about how their effort affect the senior worker's earnings, and when they have incomplete information about how their effort affects the earnings of the senior worker. These attempts, however, are more frequent and pronounced under incomplete information. The evidence collected from an incentive-compatible questionnaire used to elicit norms against exploitation suggests an explanation for this behavior: senior workers seem to consider small levels of exploitation as socially acceptable when junior workers cannot detect they are being exploited. To the best of our knowledge, this is the first empirical evidence that the content of norms may depend on the information that individuals have at their disposal.

The attempts to exploit junior workers are unsuccessful under complete information. The reason is that most junior workers disobey suggestions by senior workers to exert an effort that would imply unequal earnings for senior and junior workers, despite the threat of being punished. Interestingly, junior workers disobey senior workers even when they have incomplete information. This is presumably because they anticipate that senior workers will try to exploit their informational advantage. The result is that, while exploitation is successful under asymmetric information, its extent is small. Most senior workers attempt to coerce junior workers into exerting high levels of effort under both informational conditions by investing significant amounts in punishing junior workers when the latter show disobedience. The willingness to coerce junior workers is more pronounced under asymmetric information. The result of exploitation and coercion is that junior workers are substantially worse off in monetary terms under asymmetric information than under symmetric information.

What do our results imply for exploitation in organizations? As mentioned in the introduction, our laboratory experiment controls for a number of factors that could affect the willingness of managers to exploit their subordinates in daily life. For this reason, generalizations should be made with care. We believe our findings suggest that exploitation may be more likely in organizations in which workers have little information about the product of their efforts relative to their managers. Greater transparency in these cases could limit the extent of exploitation, not only because workers will be more likely to resist exploitation, but also because managers may be less willing to act in a way that would be socially unacceptable. This may be either because individuals suffer a cost when they violate social norms or because socially unacceptable behavior could cost managers their job. ${ }^{20}$

\footnotetext{
${ }^{20}$ For two experiments on the pro-social effect of democratic or organizational control see Bolle and Vogel (2011) and Hamman et al. (2011).
} 


\section{References}

[1] Abbink, K. (2006). Laboratory Experiments on Corruption. In S. Rose-Ackerman (ed), International Handbook on the Economics of Corruption, Edward Elgar Publishing Inc.

[2] Andreoni, J. Rao, J.M. (2011). The Power of Asking: How Communication Affects Selfishness, Empathy and Altruism. Journal of Public Economics 95, 513-520.

[3] Bachman, R. (1994). Violence and Theft in the Workplace. Crime Data Brief: National Crime Victimization Survey. Washington, DC: Bureau of Justice statistics, U.S. Department of Justice.

[4] Baron, R. A., Neuman, J.H., Geddes, D. (1999). Social and Personal Determinants of Workplace Aggression: Evidence for the Impact of Perceived Injustice and the Type-A Behavior Pattern. Aggressive Behaviour 25(4), 281-296.

[5] Bernhard, H., Fehr, E., Fischbacher, U. (2006). Group Affiliation and Altruistic Norm Enforcement. American Economic Review 96(2), 217-221.

[6] Bewley, T. F. (1999). Why Wages Don't Fall During a Recession. Cambridge, MA: Harvard University Press.

[7] Brandts, J., Cooper, D. (2006). A Change Would Do You Good: An Experimental Study of How to Overcome Coordination Failure in Organzations, American Economic Review 96, 669-693.

[8] Boles, T. L., Croson, R. T. A., and Murnighan, J. K. (2000). Deception and Retribution in Repeated Ultimatum Bargaining Organizational Behavior and Human Decision Processes 83 (2), 235-259.

[9] Bolle, F., Breitmoser, Y., Schlächter, S. (2011). Extortion in the Laboratory. Journal of Economic Behavior \& Organization 78(3), 207-218.

[10] Bolle, F,. and Vogel, C. (2011). Power Comes with Responsibility - Or does it? Public Choice, 148(3), 459-470.

[11] Burks, S. V., Krupka, E.L. (2012). Behavioral Economic Field Experiments Can Identify Normative Alignments and Misalignments within a Corporate Hierarchy: Evidence from the Financial Services Industry. Management Science 58, 203-217.

[12] Cameron, L., Chaudhuri, A., Erkal, N., Gangadharan, L. (2009). Propensities to Engage in and Punish Corrupt Behavior: Experimental Evidence from Australia, India, Indonesia and Singapore. Journal of Public Economics 93(7-8), 843-851.

[13] Castillo, M., Petrie R. (2010). Discrimination in the lab: Does information trump appearance? Games and Economic Behavior 68, 50-59. 
[14] Coleman, J. (1990). Foundations of Social Theory. Cambridge MA: Harvard University Press.

[15] Croson, R.T.A. (1996). Information in Ultimatum Games: An Experimental Study. Journal of Economic Behavior \& Organization 30, 197-212.

[16] Croson, R. T. A., Boles, T. L., and Murnighan, J. K. (2003). Cheap Talk in Bargaining Experiments: Lying and Threats in Ultimatum Games. Journal of Economic Behavior $\mathcal{C}_{3}$ Organization 51, 143-159

[17] Day J. (1963). Authority. Political Studies 11, 257-271.

[18] Denant-Boemont, L., Masclet, D., Noussair, C. (2007). Punishment, Counterpunishment and Sanction Enforcement in a Social Dilemma Experiment. Economic Theory 33(1), 145-167.

[19] Falk, A., Kosfeld, M. (2006). The Hidden Cost of Control. American Economic Review 96 (5), 1611-1630.

[20] Fehr, E., Kirchsteiger, G., Riedl, A. (1993). Does Fairness Prevent Market Clearing? An Experimental Investigation. Quarterly Journal of Economics 108 (2), 437-459.

[21] Fehr, E., \& Schmidt, K. (1999). A Theory of Fairness, Competition and Cooperation. Quarterly Journal of Economics 114, 817-868.

[22] Fischbacher, U. (2007). z-Tree: Zurich Toolbox for Ready-Made Economic Experiments. Experimental Economics 10 (2), 171-178.

[23] Forsythe, R. L., Horowitz, J., Savin, N. E., Sefton, M. (1994). Fairness in Simple Bargaining Games. Games and Economic Behavior, 6, 347-369.

[24] Goette, L., Huffman, D., Meier, S., Sutter, M. (2012). Competition between Organizational Groups: Its Impact on Altruistic and Anti-Social Motivations. Management Science 58, 948960.

[25] Greenberg, L., Barling, J. (1999). Predicting Employee Aggression Against Coworkers, Subordinates and Supervisors: The Roles of Person Behaviors and Perceived Workplace Factors. Journal of Organizational Behavior 20, 897-913.

[26] Güth, W., Huck, S., Ockenfels, P. (1996). Two-level Ultimatum Bargaining with Incomplete Information: An Experimental Study. Economic Journal 106 (436), 593-604.

[27] Hamman, J., Loewenstein, G., Weber, R.A. (2010). Self-interest through Delegation: An Additional Rationale for the Principal-Agent Relationship. American Economic Review 100(4), 1826-1846.

[28] Hamman, J., Weber, R., and Woon, J. (2011). An Experimental Investigation of Electoral Delegation and the Provision of Public Goods. American Journal of Political Science 55(4), 738-52. 
[29] Hoad, C.D. (1993). Violence at Work: Perspectives from Research Among 20 British Employers. Security Journal, 4, 64-86.

[30] Hoffman, E., McCabe, K., Shachat, K., Smith, V. (1994). Preferences, Property rights, and Anonymity in Bargaining Games. Games and Economic Behavior 7 (3), 346-380.

[31] International Labour Organization (2009). The Cost of Coercion. Available online at: http://www.ilo.org/sapfl/Informationresources/ILOPublications/WCMS_106268/langen/index.htm.

[32] Kagel, J. H., Kim, C., Moser, D. (1996). Fairness in Ultimatum Games with Asymmetric Information and Asymmetric Payoffs. Games and Economic Behavior 13, 100-110.

[33] Krupka, E.L., Weber, R.A. (in press). Identifying Social Norms using Coordination Games: Why does Dictator Game Sharing Vary? Journal of the European Economic Association.

[34] Mitzkewitz, M., Nagel, R. (1993). Envy, Greed and Anticipation in Ultimatum Games with Incomplete Information: An Experimental Study. International Journal of Game Theory. 22, 171-198.

[35] Nikiforakis, N. (2008). Punishment and Counter-Punishment in Public Good Games: Can We Really Govern Ourselves? Journal of Public Economics 92, 91-112.

[36] Nikiforakis, N., Normann, H.T. (2008). A Comparative Statics Analysis of Punishment in Public Good Experiments. Experimental Economics 11, 358-369.

[37] Oechssler, J. (2013). Finitely repeated games with social preferences, forthcoming Experimental Economics, DOI 10.1007/s10683-012-9336-6.

[38] Rapoport, A., Sundali, J.A. (1996). Ultimatums in Two-Person Bargaining with One-Sided Uncertainty: Offer Games. International Journal of Game Theory 25, 475-494.

[39] Rapoport, A., Sundali, J.A., Seale, D.A. (1996). Ultimatums in Two-Person Bargaining with One-Sided Uncertainty: Demand Games. Journal of Economic Behavior ES Organization 30, 173-196.

[40] Schmitt, P.M. (2004). On Perceptions of Fairness: The Role of Valuations, Outside Options, and Information in Ultimatum Bargaining. Experimental Economics 7, 49-73.

[41] Straub, P., Murnighan, K. (1995). An Experimental Investigation of Ultimatum Games: Information, Fairness, Expectations, and Lowest Acceptable Offers. Journal of Economic Behavior \& Organization 27, 345-364.

[42] Tormey, J. F. (1974). Exploitation, Oppression and Self-Sacrifice. Philosophical Forum 5, 206221. 
[43] Vafaï, K. (2002). Preventing Abuse of Authority in Hierarchies. International Journal of Industrial Organization 20(8), 1143-1166.

[44] Weber, R.A. (2006). Managing Growth to Achieve Efficient Coordination in Large Groups. American Economic Review 96(1), 114-126.

[45] Wertheimer, A. (1987) Coercion. Princeton: Princeton University Press.

[46] Wertheimer, A. (1996). Exploitation. Chichester, West Sussex, UK: Princeton University Press.

[47] Wertheimer, A. (2008) Exploitation. Published in The Stanford Encyclopedia of Philosophy, edited by Edward N. Zalta. Available online at: http://plato.stanford.edu/archives/fall2008/entries/exploitation/. 


\section{Appendix}

Table A.1 - Summary statistics from questionnaire in Part 3

\begin{tabular}{|c|c|c|c|c|}
\hline \multirow{2}{*}{ Questions } & \multicolumn{2}{|c|}{ SYM treatment } & \multicolumn{2}{|c|}{ ASYM treatment } \\
\hline & Mean & Mode & Mean & Mode \\
\hline $\begin{array}{l}\text { 1. Suppose in Part 1, Bob knows exactly how Adam's earnings depend } \\
\text { on Bob's effort choice. Adam asked Bob to choose an effort level of } 3 \text {. } \\
\text { How socially acceptable is Adam s demand? }\end{array}$ & $\begin{array}{c}1.05 \\
(0.22)\end{array}$ & 1 & $\begin{array}{c}1.23 \\
(0.42)\end{array}$ & 1 \\
\hline $\begin{array}{l}\text { 2. Suppose in Part } 1 \text {, Bob knows exactly how Adam's earnings depend } \\
\text { on Bob's effort choice. Adam asked Bob to choose an effort level of } 5 \text {. } \\
\text { How socially acceptable is Adam's demand? }\end{array}$ & $\begin{array}{c}2.20 \\
(0.67)\end{array}$ & 2 & $\begin{array}{c}2.05 \\
(0.75)\end{array}$ & 2 \\
\hline $\begin{array}{l}\text { 3. Suppose in Part } 1 \text {, Bob does NOT know how Adam's earnings } \\
\text { depend on Bob's effort choice. Adam asked Bob to choose an effort } \\
\text { level of } 3 \text {. How socially acceptable is Adam's demand? }\end{array}$ & $\begin{array}{c}\text { Not } \\
\text { asked }\end{array}$ & $\begin{array}{c}\text { Not } \\
\text { asked }\end{array}$ & $\begin{array}{c}1.38 \\
(0.63)\end{array}$ & 1 \\
\hline $\begin{array}{l}\text { 4. Suppose in Part } 1 \text {, Bob does NOT know how Adam's earnings } \\
\text { depend on Bob's effort choice. Adam asked Bob to choose an effort } \\
\text { level of } 5 \text {. How socially acceptable is Adam's demand? }\end{array}$ & $\begin{array}{c}\text { Not } \\
\text { asked }\end{array}$ & $\begin{array}{c}\text { Not } \\
\text { asked }\end{array}$ & $\begin{array}{c}1.53 \\
(0.60)\end{array}$ & 1 \\
\hline $\begin{array}{l}5^{*} \text {. In Part } 1 \text {, Adam asked Bob to choose an effort level of } 5 \text {. Bob } \\
\text { chose an effort level of } 3 \text {. Adam reduced Bob's earnings until finally } \\
\text { Bob chose a level of } 5 . \text { In Part } 2 \text {, Bob asked Adam to choose an effort } \\
\text { level of } 5 \text {. How socially acceptable is Bob's demand? }\end{array}$ & $\begin{array}{c}1.55 \\
(0.75)\end{array}$ & 1 & $\begin{array}{c}1.57 \\
(0.78)\end{array}$ & 1 \\
\hline $\begin{array}{l}6^{*} \text {. In Part } 1 \text {, Adam asked Bob to choose an effort level of } 5 \text {. Bob } \\
\text { chose an effort level of } 3 \text {. Adam reduced Bob's earnings until finally } \\
\text { Bob chose a level of } 5 \text {. In Part } 2 \text {, Bob asked Adam to choose an effort } \\
\text { level of } 7 \text { instead. How socially acceptable is Bob's demand? }\end{array}$ & $\begin{array}{c}2.93 \\
(0.73)\end{array}$ & 3 & $\begin{array}{c}2.88 \\
(0.79)\end{array}$ & 3 \\
\hline $\begin{array}{l}7^{*} \text {. In Part } 1 \text {, Adam asked Bob to choose an effort level of } 3 \text {. Bob } \\
\text { chose an effort level of } 3 \text {. Adam did not reduce Bob s earnings. In Part } \\
2 \text {, Bob asked Adam to choose an effort level of } 3 \text {. How socially } \\
\text { acceptable is Bob's demand? }\end{array}$ & $\begin{array}{c}1.05 \\
(0.22)\end{array}$ & 1 & $\begin{array}{c}1.15 \\
(0.53)\end{array}$ & 1 \\
\hline $\begin{array}{l}8^{*} \text {. In Part } 1 \text {, Adam asked Bob to choose an effort level of } 3 \text {. Bob } \\
\text { chose an effort level of } 3 \text {. Adam did not reduce Bob s earnings. In Part } \\
2 \text {, Bob asked Adam to choose an effort level of } 5 \text { instead. How socially } \\
\text { acceptable is Bob's demand? }\end{array}$ & $\begin{array}{c}2.73 \\
(0.51)\end{array}$ & 3 & $\begin{array}{c}2.60 \\
(0.78)\end{array}$ & 3 \\
\hline $\begin{array}{l}9 * \text { In Part } 1 \text {, Adam asked Bob to choose an effort level of } 3 \text {. Bob } \\
\text { chose an effort level of } 3 \text {. Adam did not reduce Bob s earnings. In Part } \\
2 \text {, Bob asked Adam to choose an effort level of } 7 \text { instead. How socially } \\
\text { acceptable is Bob's demand? }\end{array}$ & $\begin{array}{c}3.63 \\
(0.54)\end{array}$ & 4 & $\begin{array}{c}3.45 \\
(0.78)\end{array}$ & 4 \\
\hline $\begin{array}{l}\text { 10*. In part } 1 \text {, Adam asked Bob to choose an effort level of } 5 \text {. Bob } \\
\text { chose an effort level of } 5 \text {. Adam did not reduce Bob s earnings. In Part } \\
2 \text {, Bob asked Adam to choose an effort level of } 3 \text { instead. How socially } \\
\text { acceptable is Bob's demand? }\end{array}$ & $\begin{array}{c}1.48 \\
(0.68)\end{array}$ & 1 & $\begin{array}{c}1.53 \\
(0.72)\end{array}$ & 1 \\
\hline
\end{tabular}

\footnotetext{
* In the case of the ASYM treatment, questions 5 to 10 had an addition of "Bob did NOT know how his effort will affect Adam's earnings" just after the second sentence. Numbers in parenthesis indicate standard deviation. Calculations are based on the responses of participants irrespective of their role in Part 1 of the experiment.
} 


\section{Experimental Instructions}

Below are the experimental instructions for the ASYM treatment. We first present the instructions for senior workers (Player $A$ in the instructions) and then those for junior workers (Player B). The instructions for the SYM treatment were appropriately adjusted and are available from the authors upon request.

\section{General Instructions (for all players)}

When entering the laboratory you drew a number which determined your seat number. In turn, your seat number determines the type of decisions you will make in the experiment.

As you will find out shortly, most participants will be allocated one of two roles (A or B). More information about the decisions of A and B will be given on a separate set of instructions.

However, one participant will be assigned a role other than A or B. We will refer to this individual as 'the monitor'. This individual will not receive the other sets of instructions that the other participants will receive. The role of this individual is to pay each participant at the end of the experiment.

The monitor will be the only one who ever will be informed about your earnings. Given that the monitor will not receive the other set of instructions, s/he will not be able to infer anything about your decisions in the experiment from your earnings. That is, no one except you will be able to tell what decisions you made during the experiment (not even the experimenters).

The monitor will receive a payment for assisting us with the experiment.

In today's experiment, the individual who will have the role of the monitor is the one who drew number '30'.

If you are the one with number 30, please raise your hand and one of the experimenters will come to you. Otherwise, please proceed to read the other set of instructions. 


\section{Instructions for Player A}

You are now taking part in an economic experiment. Please do not communicate with other participants during the experiment. Should you have any questions, please raise your hand and one of us will come to assist you. The amount of money you earn from this experiment depends on your decisions and those made by others in the experiment. It is therefore important that you take your time to understand the instructions. You may receive further instructions later. If you do, please read those also carefully.

During the experiment your earnings will be calculated in Experimental Monetary Units (EMU) where 9 EMU $=1$ Australian Dollar (AUD). All EMU earned during the experiment will be summed up, exchanged into AUD, and paid to you in cash in private immediately at the end of the experiment. No one except the participant selected to be the monitor will ever be informed about your earnings. Given that the monitor will not receive these instructions, s/he will not be able to infer anything about your decisions in the experiment from your earnings.

There are two types of players in this experiment, which lasts 10 periods. We will refer to them as Player A and Player B. At the beginning of the experiment, you were randomly assigned the role of Player A. Roles will remain the same throughout the 10 periods. Player A and Player B differ in the decisions they can make.

At the beginning of the experiment, the computer will also randomly match you with another individual in the laboratory. Each participant will be matched with an individual that has been assigned the opposite role. That is, you will be matched with an individual that has been assigned the role of Player B. You will remain matched with the same individual throughout the 10 periods. You will never find out the identity of the other individual and the other individual will never find out your identity.

Each of the 10 periods is divided into 3 stages. In what follows, we explain the decisions each type of player must take in each stage and how these decisions translate into earnings.

\section{Stage 1}

In stage 1, you (Player A) will indicate the level of effort that you would like Player B to choose in stage 2. There are eleven effort levels. The lowest effort level is 0 and the highest one is 10 . You can ask Player B to select any effort level from 0 to 10.

The higher the level of effort chosen by Player B in stage 2, the higher will be your earnings. So far, all of this is also known to Player B. The following information and that contained in the table "Your Earnings at the End of Stage 2", however, is only known to you. In particular, you know that every additional unit of effort chosen by Player B will increase your earnings by 2 EMU. Your exact earnings at the end of the second stage are given in the following table.

Your Earnings at the End of Stage 2

\begin{tabular}{|llllllllllll|}
\hline $\begin{array}{l}\text { Effort level } \\
\text { chosen by B }\end{array}$ & $\mathbf{0}$ & $\mathbf{1}$ & $\mathbf{2}$ & $\mathbf{3}$ & $\mathbf{4}$ & $\mathbf{5}$ & $\mathbf{6}$ & $\mathbf{7}$ & $\mathbf{8}$ & $\mathbf{9}$ & $\mathbf{1 0}$ \\
\hline Your Earnings & 12 & 14 & 16 & 18 & 20 & 22 & 24 & 26 & 28 & 30 & 32 \\
\hline
\end{tabular}




\section{Stage 2}

In stage 2, Player B will be informed about the level of effort that you would like Player $B$ to choose. Player B must then choose an effort level. The effort level can be any effort level between 0 and 10.

The higher the level of effort chosen by Player B in stage 2, the lower will be his/her earnings. In particular, every additional unit of effort chosen by Player B will decrease his/her earnings by 2 EMU. The exact earnings of Player $\mathrm{B}$ at the end of the second stage are given in the following table.

Player B's Earnings at the End of Stage $\mathbf{1}$
\begin{tabular}{|lllllllllllll|}
\hline $\begin{array}{l}\text { Effort level } \\
\text { chosen by B }\end{array}$ & $\mathbf{0}$ & $\mathbf{1}$ & $\mathbf{2}$ & $\mathbf{3}$ & $\mathbf{4}$ & $\mathbf{5}$ & $\mathbf{6}$ & $\mathbf{7}$ & $\mathbf{8}$ & $\mathbf{9}$ & $\mathbf{1 0}$ \\
\hline $\begin{array}{l}\text { Player B's } \\
\text { Earnings }\end{array}$ & 24 & 22 & 20 & 18 & 16 & 14 & 12 & 10 & 8 & 6 & 4 \\
\hline
\end{tabular}

Remember that Player B does not know exactly how his/her choice of an effort level affects your earnings. However, Player B knows the exact information included in table "Player B's Earnings at the End of Stage 2" and s/he also knows that you have the information included in the table.

For example, if Player B chooses an effort level of 6, s/he knows that his/her earnings at the end of stage 2 will be 12. Player B knows that you know this too. Yet Player B does not know how much exactly you will earn. But s/he knows that your earnings are increasing as effort increases.

\section{Stage 3}

In stage 3, you must decide whether to reduce the earnings of Player B or simply leave them unchanged. In particular, you will be asked to state by how much you would like to reduce player B's earnings. If you do not wish to reduce the earnings of Player B, then you must choose ' 0 EMU'. Otherwise, you must specify the number of EMU by which you would like to reduce Player B's earnings. You cannot reduce Player B's earnings below 0.

Every 1 EMU that you reduce Player B's earnings, will reduce your earnings by 0.20 EMU. This is known to Player B when making decisions in Stage 2. In particular, Player B has the same information as you do regarding Stage 3.

The earnings of each player at the end of a period will be calculated as follows:

Your Earnings at the end of a period =

Earnings at the end of Stage $2-0.20 *$ (Number of EMU by which Player B's earnings were reduced) Or

$12+2 *($ Effort Level Chosen by Player B) $-0.20 *$ (Number of EMU by which Player B's earnings were reduced)

Earnings of Player $B$ at the end of a period $=$

Earnings at the end of Stage 2 - (Number of EMU by which Player B's earnings were reduced by you) Or

24 - 2*(Effort Level Chosen by Player B) - (Number of EMU by which Player B's earnings were reduced by you) 
Remember that there will be 10 periods and that you will always interact with the same individual. Also, remember that roles will remain the same across periods. For the first two periods you will be given 60 seconds to make each decision. Thereafter, you will be given 45 seconds for each decision.

Below are two examples to help you understand the experiment. The examples are not meant as a guide for behaviour in the experiment.

\section{Example 1}

Assume that in stage 1 you ask Player B to choose an effort level of 7. In stage 2, Player B chose an effort level of 5. Assume further that you decided to reduce Player B's earnings by 10 EMU. Your earnings at the end of this period will be

$12+2 *(5)-0.20 *(10)=20.00$ EMU

\section{Example 2}

Assume that in stage 1 you ask Player B to choose an effort level of 2. Assume that in stage 2 Player B chose an effort level of 2. Assume further that you decided to reduce Player B's earnings by 5 EMU. Your earnings at the end of this period will be

$12+2 *(2)-0.20 *(5)=15.00 \mathrm{EMU}$

If you have any questions, please raise your hand to attract the attention of one of the experimenters. Otherwise, please proceed to answer the questions on the following page. Once you have finished answering the questions, please raise your hand and one of the experimenters will come to check your answer. 


\section{Control Questions}

1. True or false: In stage 2 Player B has to choose the level of effort asked by you.

True

False

2. True or false: In stage 3 you can reduce B's earnings to 0 .

True $\quad$ False

3. True or false: The effort level asked by you in stage 1 determines your earnings.

True $\quad$ False

4. True or false: Player B knows exactly how much you will earn when s/he chooses an effort level.

True $\quad$ False

5. True or false: Player B knows the exact implications of earnings reduction in stage 3 for his/her and your earnings.

True $\quad$ False

6. True or false: No one (not even the monitor) will be able to identify the decisions I made in the experiment.

True $\quad$ False

7. What will be your earnings if Player B chooses an effort level of 3 and you do not reduce B's earnings?

Your earnings

8. What will be your earnings if Player B chooses an effort level of 3 and you reduce B's earnings by 5 EMU?

Your earnings

9. What will be your earnings if Player B chooses an effort level of 8 and you do not reduce B's earnings?

Your Earnings

10. What will be your earnings if Player B chooses an effort level of 8 and you reduce B's earnings by 5 EMU?

Your earnings 
This is the second part of the experiment. Any earnings from Part 2 will be added to your earnings from Part 1.

In the second part, you will continue to interact with the same person as in the first part. The task in the second part is the same as that in the first part. The second part also lasts $\mathbf{1 0}$ periods. You are still Player A.

There is one important difference between the first and the second part: The decisions that Players A and $B$ have to make will be exactly reversed. In particular, Player B will now be the one asking you (Player A) what level of effort to choose in stage 2, and whether or not to reduce your earnings in stage 3. You will be the one choosing an effort level in stage 2 from 0 to 10.

Player B's earnings are calculated in the same way as your earnings in Part 1. Similarly, your earnings are calculated in the same way as Player B's earnings in Part 1.

In contrast to Part 1, now both players have precise information about the earnings of each other.

In particular, every additional unit of effort you choose will increase Player B's earnings by 2 EMU. The exact earnings of Player B at the end of the second stage are given in the following table.

Player B's Earnings at the End of Stage $\mathbf{2}$
\begin{tabular}{|lllllllllllll|}
\hline $\begin{array}{l}\text { Effort level } \\
\text { chosen by you }\end{array}$ & $\mathbf{0}$ & $\mathbf{1}$ & $\mathbf{2}$ & $\mathbf{3}$ & $\mathbf{4}$ & $\mathbf{5}$ & $\mathbf{6}$ & $\mathbf{7}$ & $\mathbf{8}$ & $\mathbf{9}$ & $\mathbf{1 0}$ \\
\hline $\begin{array}{l}\text { Player B's } \\
\text { Earnings }\end{array}$ & 12 & 14 & 16 & 18 & 20 & 22 & 24 & 26 & 28 & 30 & 32 \\
\hline
\end{tabular}

Furthermore, the higher the level of effort you choose in stage 2, the lower will be your earnings. In particular, every additional unit of effort chosen by you will decrease your earnings by 2 EMU. Your exact earnings at the end of the second stage are given in the following table. 
Your Earnings at the End of Stage 2

\begin{tabular}{|llllllllllll|}
\hline $\begin{array}{l}\text { Effort level } \\
\text { chosen by you }\end{array}$ & $\mathbf{0}$ & $\mathbf{1}$ & $\mathbf{2}$ & $\mathbf{3}$ & $\mathbf{4}$ & $\mathbf{5}$ & $\mathbf{6}$ & $\mathbf{7}$ & $\mathbf{8}$ & $\mathbf{9}$ & $\mathbf{1 0}$ \\
\hline Your Earnings & 24 & 22 & 20 & 18 & 16 & 14 & 12 & 10 & 8 & 6 & 4 \\
\hline
\end{tabular}

To summarize:

\section{Earnings of Player $B$ at the end of a period $=$}

$12+2 *$ (Effort Level Chosen by you) $-0.20 *$ (Number of EMU by which your earnings were reduced)

Your Earnings at the end of a period $=$

$24-2 *$ (Effort Level Chosen by you) - (Number of EMU by which your earnings were reduced by Player B)

For the first two periods you will be given 60 seconds to make each decision. Thereafter, you will be given 45 seconds for each decision.

\section{Important Note:}

There will also be a third and final part. The task in Part 3 will be different to that in Parts 1 and 2. In Part 3, you will be asked to make different decisions and, most importantly, you will NOT be matched with one particular individual.

If you have any questions, please raise your hand to attract the attention of one of the experimenters. Otherwise, please proceed to answer the questions on the following page. Once you have finished answering the questions, please raise your hand and one of the experimenters will come to check your answer. 


\section{Control Questions}

1. True or false: The decisions and the earnings of Player B in Part 2 are the same as yours in Part 1.

True False

2. True or false: I will be matched with a different person in Part 2 than I was in Part 1.

True $\quad$ False

3. True or false: The task in Part 3 is different to that in Parts 1 and 2, and I will not be matched with the same individual as in Parts 1 and 2.

True $\quad$ False

4. What will be your earnings if you choose an effort level of 8 and Player B does not reduce your earnings?

Your Earnings

5. What will be your earnings if you choose an effort level of 8 and Player B reduces your earnings by 5 EMU?

Your Earnings 


\section{Instructions (for both Player A and B) - Part 3}

This is the third and final part of the experiment. After this part is over you will be asked to fill in a brief questionnaire while the participant randomly selected to be the monitor will be preparing your payments.

As explained previously, the task in this part is different from that in Parts 1 and 2. The instructions are the same for all participants.

In this part of the experiment, you will be asked to characterize the decisions of an individual that we will call 'Bob'. Bob is matched with an individual that we will call 'Adam'. Note that Adam and Bob are not real people and the decisions ascribed to them are not that of any particular individual.

Adam is assigned the role of Player A and Bob is assigned the role of Player B in Part 1 of the experiment. Adam has no knowledge of the content of Part 2 when asking Bob to choose a level of effort. Adam can reduce Bob's earnings after observing Bob's choice if he desires. The earnings consequences of choosing a particular level of effort are the same as in Parts 1 and 2.

Your task in this part will be to characterize Adam’s or Bob’s decisions in 10 different scenarios.

Adam's or Bob's decisions can be characterized as "socially acceptable" or "socially unacceptable" By socially acceptable, we mean decisions that most people in this room would consider acceptable. A decision would be socially unacceptable if most people in this room would consider it unacceptable.

Example: In Part 1, Adam asked Bob to choose an effort level of X. Bob chose a lower effort level than X. After Adam reduced Bob's earnings a few times, Bob decided to choose an effort level of X as asked. In Part 2, Bob asked Adam to choose an effort level of Y. Do you think Bob's request in the Part 2 is (i) very socially acceptable, (ii) somewhat socially acceptable, (iii) somewhat socially unacceptable, and (iv) very socially unacceptable?

You will also be asked to characterize Adam's requests in Part 1. You will be asked to do this in cases when Bob knew how his effort affected Adam's earnings and when Bob did not know.

\section{How are payments determined in Part 3?}

In this part, you will be presented with 10 scenarios involving Adam's and Bob's decisions. In each scenario, you need to characterize Adam's or Bob's decisions. At the end of this part, the computer will randomly select one of the 10 scenarios.

If your characterization in the randomly selected scenario is the same as the characterization given by most participants in today's session, you will earn 5 AUD (that is, 45 EMU). This amount will be added to your earnings from Parts 1 and 2, and paid to you in cash at the end of the experiment. In other words, if your characterization coincides with the most common characterization, you will receive 5 AUD. If your characterization is different from the most common characterization, your earnings from this part of the experiment will be 0 . 
Example: Assume that 12 people characterized Bob's request in the Part 2 as "very socially acceptable", 11 people characterized it as "somewhat socially acceptable", and no one characterized Bob's request as "somewhat socially unacceptable" or "very socially unacceptable". If you characterized Bob's request as "very socially acceptable", 13 people will have given this characterization. As this is the most common characterization, you will earn 5 AUD. If you characterized Bob's request as "somewhat socially acceptable", 12 people will have given this characterization. In this case, there are two equally common characterizations. As your characterization is one of the most common, you will earn 5 AUD. If, however, you characterized Bob's request as "somewhat socially unacceptable" or "very socially unacceptable" then the most common characterization (very socially acceptable) would be different to yours and, therefore your earnings would be 0 AUD.

To summarize, in this part you will be asked to characterize the decisions of an individual in 10 different scenarios. At the end of Part 3, the computer will randomly select one of the 10 scenarios. If your characterization in the randomly selected scenario coincides with the most common characterization amongst all participants in today's session you will receive 5 AUD. Otherwise, your earnings from this part of the experiment will be 0 .

If you have any questions, please raise your hand and one of the experimenters will come to you. 


\section{Instructions for Player B}

You are now taking part in an economic experiment. Please do not communicate with other participants during the experiment. Should you have any questions, please raise your hand and one of us will come to assist you. The amount of money you earn from this experiment depends on your decisions and those made by others in the experiment. It is therefore important that you take your time to understand the instructions. You may receive further instructions later. If you do, please read those also carefully.

During the experiment your earnings will be calculated in Experimental Monetary Units (EMU) where 9 EMU = 1 Australian Dollar (AUD). All EMU earned during the experiment will be summed up, exchanged into AUD, and paid to you in cash in private immediately at the end of the experiment. No one except the participant selected to be the monitor will ever be ever informed about your earnings. Given that the monitor will not receive these instructions, s/he will not be able to infer anything about your decisions in the experiment from your earnings.

There are two types of players in this experiment, which lasts 10 periods. We will refer to them as Player A and Player B. At the beginning of the experiment, you were randomly assigned the role of Player $B$. Roles will remain the same throughout the $\mathbf{1 0}$ periods. Player A and Player B differ in the decisions they can make.

At the beginning of the experiment, the computer will also randomly match you with another individual in the laboratory. Each participant will be matched with an individual that has been assigned the opposite role. That is, you will be matched with an individual that has been assigned the role of Player A. You will remain matched with the same individual throughout the 10 periods. You will never find out the identity of the other individual and the other individual will never find out your identity.

Each of the 10 periods is divided into 3 stages. In what follows, we explain the decisions each type of player must take in each stage and how these decisions translate into earnings.

\section{Stage 1}

In stage 1, Player A will indicate the level of effort that s/he would like you (Player B) to choose in stage 2. There are eleven effort levels. The lowest effort level is 0 and the highest one is 10 . Player A can ask you to select any effort level from 0 to 10.

The higher the level of effort you choose in stage 2, the higher will be the earnings of Player A. While you will not know the exact earnings of Player A, Player A knows exactly the implications of your choice for his/her earnings.

\section{Stage 2}

In stage 2, you will be informed about the level of effort that Player A would like you to choose. You must then choose an effort level. The effort level can be any effort level between 0 and 10 . 
The higher the level of effort you choose in stage 2, the lower will be your earnings. In particular, every additional unit of effort you choose will decrease your earnings by 2 EMU. Your exact earnings at the end of the second stage are given in the following table.

\begin{tabular}{|llllllllllll|}
\hline $\begin{array}{l}\text { Effort level } \\
\text { chosen by you }\end{array}$ & $\mathbf{0}$ & $\mathbf{1}$ & $\mathbf{2}$ & $\mathbf{3}$ & $\mathbf{4}$ & $\mathbf{5}$ & $\mathbf{6}$ & $\mathbf{7}$ & $\mathbf{8}$ & $\mathbf{9}$ & $\mathbf{1 0}$ \\
\hline Your Earnings & 24 & 22 & 20 & 18 & 16 & 14 & 12 & 10 & 8 & 6 & 4 \\
\hline
\end{tabular}

The information about your earnings is also available to Player A. Remember, however, that you have not been given precise information about Player A's earnings (apart from the fact that they are increasing in the effort chosen by you).

For example, if you choose an effort level of 6, your earnings at the end of stage 2 will be 12 . Player A knows this too. However, you do not know how much exactly Player A will earn. Player A knows exactly how much s/he will earn if you choose an effort of 6.

\section{Stage 3}

In stage 3, Player A must decide whether to reduce your earnings or simply leave them unchanged. In particular, Player A will be asked to state by how much s/he would like to reduce your earnings. If Player A does not wish to reduce your earnings, then s/he must choose ' 0 EMU'. Otherwise, Player A must specify the number of EMU by which s/he would like to reduce your earnings. Player A cannot reduce your earnings below 0.

Every 1 EMU that Player A reduces your earnings, will reduce Player A's earnings by 0.20 EMU. This is known to Player A when making decisions in Stages 1 and 3.

Your earnings at the end of a period will be calculated as follows:

\section{Your earnings at the end of a period $=$}

Earnings at the end of Stage 2 - (Number of EMU by which your earnings were reduced by Player A) Or

24 - 2*(Effort Level Chosen by you) - (Number of EMU by which your earnings were reduced by Player A)

Remember that there will be 10 periods and that you will always interact with the same individual. Also, remember that roles will remain the same across periods. For the first two periods you will be given 60 seconds to make each decision. Thereafter, you will be given 45 seconds for each decision.

Below are two examples to help you understand the experiment. The examples are not meant as a guide for behaviour in the experiment.

\section{Example 1}

Assume that in stage 1 Player A asks you to choose an effort level of 7. In stage 2, you chose an effort level of 5. Assume further that Player A decided to reduce your earnings by 10 EMU. Your earnings at the end of this period will be

$$
24-2 *(5)-10=4.00 \text { EMU }
$$




\section{Example 2}

Assume that in stage 1 Player A asks you to choose an effort level of 2. Assume that in stage 2 you chose an effort level of 2. Assume further that Player A decided to reduce your earnings by 5 EMU. Your earnings at the end of this period will be

$24-2 *(2)-5=15.00$ EMU

If you have any questions, please raise your hand to attract the attention of one of the experimenters. Otherwise, please proceed to answer the questions on the following page. Once you have finished answering the questions, please raise your hand and one of the experimenters will come to check your answer. 


\section{Control Questions}

1. True or false: In stage 2 you have to choose the level of effort asked by Player A.

True

False

2. True or false: In stage 3 Player A can reduce your earnings to 0.

True $\quad$ False

3. True or false: The effort level asked by Player A in stage 1 determines his/her earnings.

True $\quad$ False

4. True or false: You know exactly how much Player A will earn when you choose an effort level.

True $\quad$ False

5. True or false: Player A knows exactly how much s/he will earn when you choose an effort level and also knows how much you will earn.

True $\quad$ False

6. True or false: No one (not even the monitor) will be able to identify the decisions I made in the experiment.

True $\quad$ False

7. What will be your earnings if you choose an effort level of 3 and Player A does not reduce your earnings?

Your Earnings

8. What will be your earnings if you choose an effort level of 3 and Player A reduces your earnings by 5 EMU?

Your Earnings

9. What will be your earnings if you choose an effort level of 8 and Player A does not reduce your earnings?

Your Earnings

10. What will be your earnings if you choose an effort level of 8 and Player A reduces your earnings by 5 EMU?

Your Earnings 
This is the second part of the experiment. Any earnings from Part 2 will be added to your earnings from Part 1.

In the second part, you will continue to interact with the same person as in the first part. The task in the second part is the same as that in the first part. The second part also lasts $\mathbf{1 0}$ periods. You are still Player $\mathbf{B}$.

There is one important difference between the first and the second part: The decisions that Players A and $B$ have to make will be exactly reversed. In particular, you will now be the one asking Player A what level of effort to choose in stage 2, and whether or not to reduce the earnings of Player A in stage 3. Player A will be the one choosing an effort level in stage 2 from 0 to 10.

Your earnings are calculated in the same way as Player A's earnings in Part 1. Similarly, Player A's earnings are calculated in the same way as your earnings in Part 1.

In contrast to Part 1 , now both players have precise information about the earnings of each other.

In particular, every additional unit of effort chosen by Player A will increase your earnings by 2 EMU. Your exact earnings at the end of the second stage are given in the following table.

Your Earnings at the End of Stage 2

\begin{tabular}{|llllllllllll|}
\hline $\begin{array}{l}\text { Effort level } \\
\text { chosen by A }\end{array}$ & $\mathbf{0}$ & $\mathbf{1}$ & $\mathbf{2}$ & $\mathbf{3}$ & $\mathbf{4}$ & $\mathbf{5}$ & $\mathbf{6}$ & $\mathbf{7}$ & $\mathbf{8}$ & $\mathbf{9}$ & $\mathbf{1 0}$ \\
\hline Your Earnings & 12 & 14 & 16 & 18 & 20 & 22 & 24 & 26 & 28 & 30 & 32 \\
\hline
\end{tabular}

Furthermore, the higher the level of effort chosen by Player A in stage 2, the lower will be his/her earnings. In particular, every additional unit of effort chosen by Player A will decrease his/her earnings by 2 EMU. The exact earnings of Player $\mathrm{A}$ at the end of the second stage are given in the following table. 
Player A's Earnings at the End of Stage 2

\begin{tabular}{|lccccccccccr|}
\hline $\begin{array}{l}\text { Effort level } \\
\text { chosen by A }\end{array}$ & $\mathbf{0}$ & $\mathbf{1}$ & $\mathbf{2}$ & $\mathbf{3}$ & $\mathbf{4}$ & $\mathbf{5}$ & $\mathbf{6}$ & $\mathbf{7}$ & $\mathbf{8}$ & $\mathbf{9}$ & $\mathbf{1 0}$ \\
\hline $\begin{array}{l}\text { Player A's } \\
\text { Earnings }\end{array}$ & 24 & 22 & 20 & 18 & 16 & 14 & 12 & 10 & 8 & 6 & 4 \\
\hline
\end{tabular}

To summarize:

Your Earnings at the end of a period $=$

$12+2 *($ Effort Level Chosen by Player A $)-0.20 *$ (Number of EMU by which Player A's earnings were reduced by you)

Earnings of Player $A$ at the end of a period $=$

24 - 2*(Effort Level Chosen by Player A) - (Number of EMU by which Player A's earnings were reduced by you)

For the first two periods you will be given 60 seconds to make each decision. Thereafter, you will be given 45 seconds for each decision.

\section{Important Note:}

There will also be a third and final part. The task in Part 3 will be different to that in Parts 1 and 2. In Part 3, you will be asked to make different decisions and, most importantly, you will NOT be matched with one particular individual.

If you have any questions, please raise your hand to attract the attention of one of the experimenters. Otherwise, please proceed to answer the questions on the following page. Once you have finished answering the questions, please raise your hand and one of the experimenters will come to check your answer. 


\section{Control Questions}

1. True or false: The decisions and the earnings of Player A in Part 1 are the same as yours in Part 2.

True False

2. True or false: I will be matched with a different person in Part 2 than in I was in Part 1.

True $\quad$ False

3. True or false: The task in Part 3 is different to that in Parts 1 and 2, and I will not be matched with the same individual as in Parts 1 and 2.

True $\quad$ False

4. What will be your earnings if Player A chooses an effort level of 8 and you do not reduce A's earnings?

Your Earnings

5. What will be your earnings if Player A chooses an effort level of 8 and you reduce A's earnings by 5 EMU?

Your Earnings 